\title{
Radon Diffusion Through Multilayer Earthen Covers: Models and Simulations
}
D. W. Mayer
C. A. Oster
R. W. Nelson
G. W. Gee

September 1981

Prepared for the U.S. Department of Energy under Contract DE-AC06-76RLO 1830

Pacific Northwest Laboratory Operated for the U.S. Department of Energy by Battelle Memorial Institute 


\title{
NOTICE
}

This report was prepared as an account of work sponsored by the United States Government. Neither the United States nor the Department of Energy, nor any of their employees, nor any of their contractors, subcontractors, or their employees, makes any warranty, express or implied, or assumes any legal liability or responsibility for the accuracy, completeness or usefulness of any information, apparatus, product or process disclosed, or represents that its use would not infringe privately owned rights.

The views. opinions and conclusions contained in this report are those of the contractor and do not necessarily represent those of the United States Government or the United States Department of Energy.

\section{PACIFIC NORTHWEST LABORATORY \\ operated by \\ BATTELLE \\ for the \\ UNITED STATES DEPARTMENT OF ENERGY \\ Under Contract DE-AC06-76RLO 1830}

\author{
Printed in the United States of America \\ Available from \\ National Technical Information Service \\ United States Department of Commerce \\ 5285 Port Royal Road \\ Springfield, Virginia 22151
}

Price: Printed Copy $\$$

*: Microfiche $\$ 3.00$

NTIS

*Pages Selling Price

001-025 $\$ \$ 4.00$

026-050 $\$ 4.50$

051-075 \$5.25

$076-100 \quad \$ 6.00$

$101-125 \quad \$ 6.50$

$126-150 \quad \$ 7.25$

$151-175 \quad \$ 8.00$

$176-200 \quad \$ 9.00$

$201-225 \quad \$ 9.25$

$226-250 \quad \$ 9.50$

$251-275 \quad \$ 10.75$

$276-300 \quad \$ 11.00$ 

D. W. Mayer
C. A. Oster
R. W. Nelson
G. W. Gee

September 1981

Prepared for the U.S. Department of Energy under Contract DE-AC06-76RLO 1830

Pacific Northwest Laboratory Richland, Washington 99352 



\section{SUIPAARY}

Pacific Northwest Laboratory is investigating the use of multilayered earthen covers for controlling radon gas emissions from uranium mill tailings. A modeling study of radon diffusion through multiple cover layers was initiated to aid in the design of cover systems that can effectively control radon emissions to a prescribed flux limit. The design considers field conditions where compaction densities and variable moisture contents in the cover control the radon flux.

The study has been conducted using a four-phase approach. The first phase develops the solution to the steady-state radon-diffusion equation in onedimension. The next phase develops the capability to model one-dimensional transient diffusion of radon gas and considers the effects of time-varying moisture content throughout the tailings pile. The third phase develops a multidimensional transient model that can be used to investigate the two- and three-dimensional aspects of radon diffusion. The final phase of the study used this analytical capability to investigate the radon flux and concentration profiles that develop in tailings piles and cover systems.

fiodeling studies have helped us understand the complex, multidimensional, radon diffusion process that occurs in covered uranium mill tailings, and have yielded several design guidelines.

1. Radon diffusion rates and required cover thicknesses for multilayer covers can be determined successfully with the analytical or numerical solutions, or both, presented in this report. Cover thickness is not related in a simple manner to the bare tailings flux, except for single layer systems. Hence, detailed calcuiations are generally needed to determine a required cover thickness for a multilayer system. The computer codes RADON1, RNDIID and RADMD can be used to conveniently solve problems of steady-state, transient, single- and multi-dimensional radon diffusion through multilayer cover systems.

2. Piaximum reduction in radon emission is achieved if the top cover layer is engineered to exhibit the lowest radon diffusion of all of the cover 
layers. However, in practice, factors such as requirements for plant cover, root zone depth, maintenance of layer moisture, and the need to prevent layer degradation by animal intrusion must be considered in a final cover design.

3. The variation of moisture content in the cover must be considered in order to assess variations in radon flux. Simulations of typical climatic conditions on an engineered cover produced moisture content changes that resulted in two-fold or greater changes in surface radon fluxes.

4. Multilayer systems generally require less total cover thickness than single cover layer systems to achieve the same flux reduction. This is true, provided that the multilayer system contains layer sequences having lower air-filled porosities than those found in the single cover system. The multilayer system described in this report contains a wet compacted clay/gravel layer, which is hydraulically isolated from the top cover soil by a rock layer that acts as a capillary barrier. When the clay/gravel is wet, radon diffusion is controlled for an extended period of time even under dry climate conditions. In contrast, a 35-fold increase in radon flux was calculated for a multilayer system containing a compacted clay/gravel layer that had drained from saturation to less than $40 \%$ saturation.

The preliminary multidimensional model results are very encouraging. We have successfully modeled radon diffusion for a discontinuous cover system and are able to match analytic solutions for concentration and fluxes with greater than 97\% accuracy. Radon escape from the edge of a tight cover is shown to cause local, elevated radon flux levels, but the elevated levels are limited to a few meters from the edge. 


\section{CONTENTS}

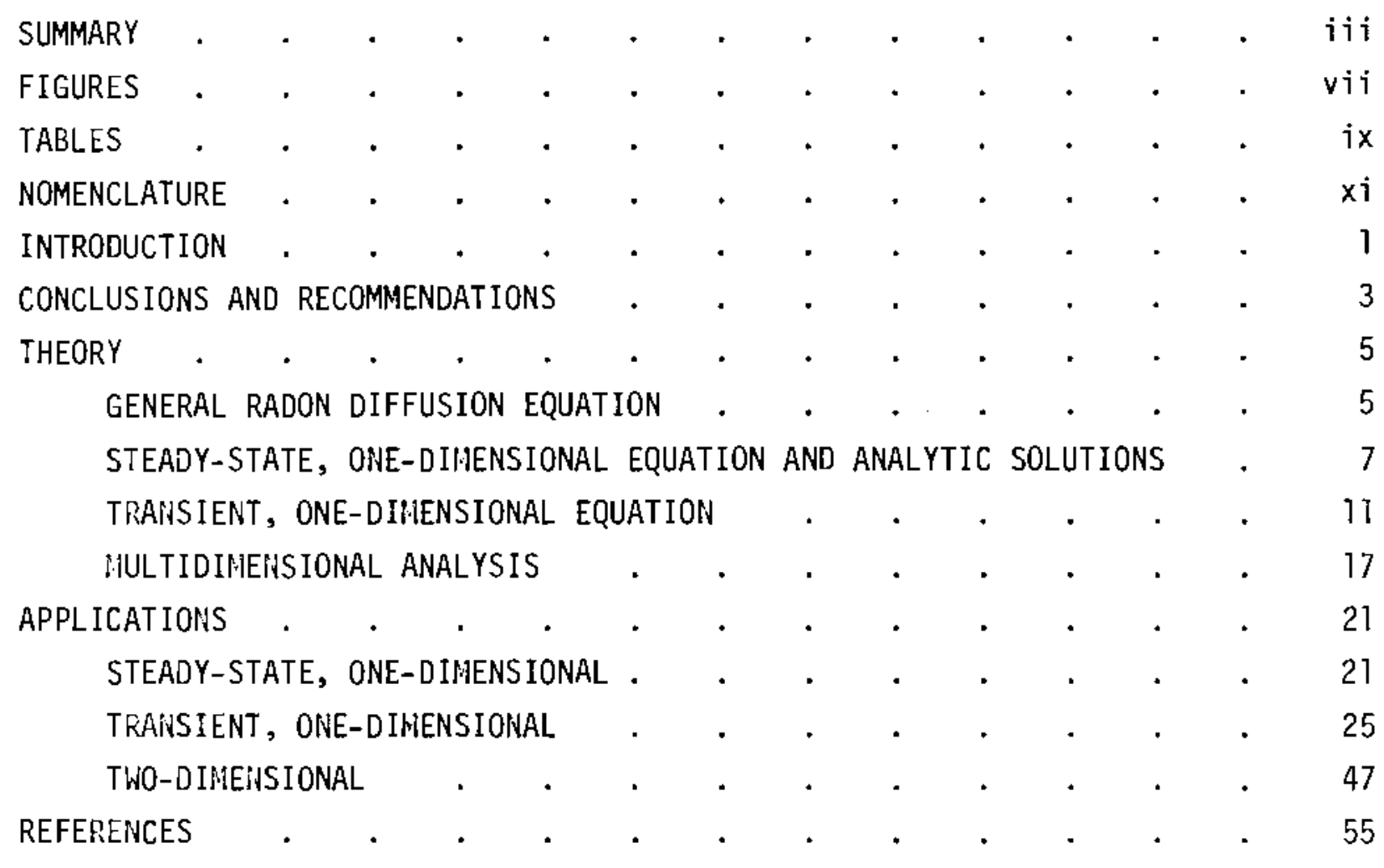





\section{FIGURES}

1 Schematic of Mill Tailings and Cover Layers . . . . . . 8

2 Finite Difference Spacing for Material Layers . . . . . . 12

3 Scaled Parameter Evaluation of "Infinite" Tailings . . . . . 22

4 Influence of $\mathrm{L}_{2},\left(\mathrm{P}_{2}-\theta_{2}\right)$ and Tailings Strength on Layer $2 . .22$

5a Surface Flux for a High Tailings Strength . . . . . . . . 26

$5 b$ Surface Flux for a Medium Tailings Strength . . . . . . . . 26

5c Surface Flux for a Low Tailings Strength _ . . . . . . . . 27

6a A+ Clay/Gravel Mix Soil-Water Characteristic, Moisture Content Versus Suction Head .

6b A+ Clay/Gravel Mix So 11 Water Characteristic, Conductivity Versus Suction Head . . . . . . . . . . . 31

7a Moisture Content Distribution, Wet Year (1979 Climate Data) lst Year . . . . . . . . . . . . . . . . . . 32

7b Moisture Content Distribution, Dry Year (1976 Climate Data) 2nd Year . . . . . . . . . . . . . . 33

7c Moisture Content Distribution, Dry Year (1976 Climate Data) 3rd Year . . . . . . . . . . . . . . 33

7d Moisture Content Distribution, Dry Year (1976 Climate Data) 4th Year . . . . . . . . . . . . . . . . . . 34

7e Moisture Content Distribution, Dry Year (1976 Climate Data) 5 th Year . . . . . . . . . . . . . . . . . . 34

8a Moisture Storage for Top $100 \mathrm{~cm}$, Wet Year (1979 Climate Data) Ist Year .

8b Moisture Storage for Top $100 \mathrm{~cm}$, Dry Year (1976 Climate Data) 2nd Year .

8c Moisture Storage for Top $100 \mathrm{~cm}$, Dry Year (1976 climate Data) -

8d Moisture Storage for Top $100 \mathrm{~cm}$, Dry Year (1976 Climate Data) 4 th Year . . . . . . . . . . . . . . . . . 36

8 Moisture Storage for Top $100 \mathrm{~cm}$, Dry Year (1976 Climate Data) 5 th Year . . . . . . . . . . . . . .

9 Moisture Storage in Clay Layer, Dry Year (1976 Climate Data) 2nd, 3rd, 4th, and 5th Years . . . . . . . . . . . 37 
10a Radon Gas Surface Flux, wet Year (1979 Climate Data) -

1st Year. . . . . . . . . . . . . 40 40

10b Radon Gas Surface Flux, Dry Year (1976 Climate Data) - 40

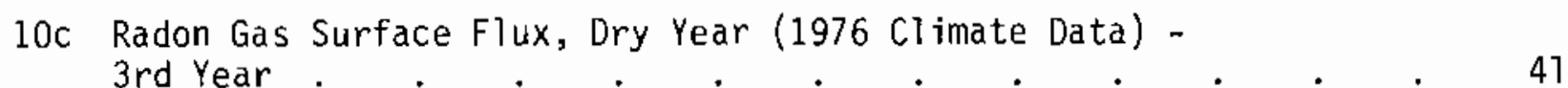

10d Radon Gas Surface Flux, Dry Year (1976 Climate Data) -
4th Year. . . . . . . . . . . . . . . . 41

10e Radon Gas Surface Flux, Dry Year (1976 Climate Data) -
5th Year. . . . . . . . . . . . . . . . . . 42

11a A-Clay/Gravel Mix Soil Water Characteristic, Moisture
Content Versus Suction Head . . . . . . . . . . . 43

11b A- Clay/Gravel Mix Soil Water Characteristic, Conductivity
Versus Suction Head. $. \quad . \quad . \quad . \quad . \quad . \quad . \quad . \quad . \quad 4$

12 Moisture Content Distribution, Dry Year (1976 Climate Data) -

13 Moisture Storage for Top $100 \mathrm{~cm}$, Dry Year (1976 Climate Data) - 46

14 Radon Gas Surface Flux, Dry Year (1976 Climate Data) - 46

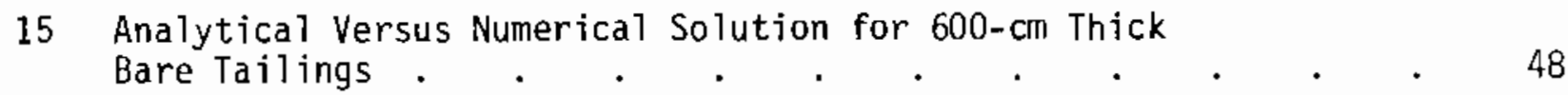

16 Two-Dimensional Grid for Discontinuous Cover Simulation . . 50

17 \begin{tabular}{l} 
Surface Flux Versus Surface Distance $(S=0$ at midpoint of \\
cover edge $)$. \\
\hline
\end{tabular}

10 Concentration Profiles for Discontinuous Cover . . . . . . 5]

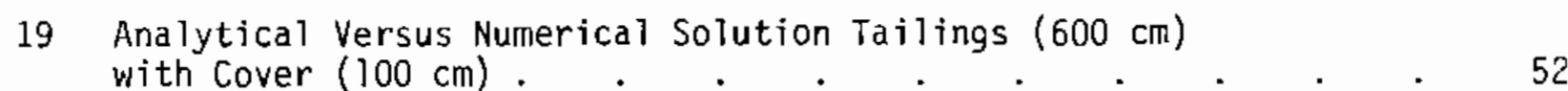

20 Analytical Versus Numerical Solution Bare Tailings $(600 \mathrm{~cm})$. . 53 


\section{TABLES}

1 Layer Characteristics . . . . . . . . . . . 24

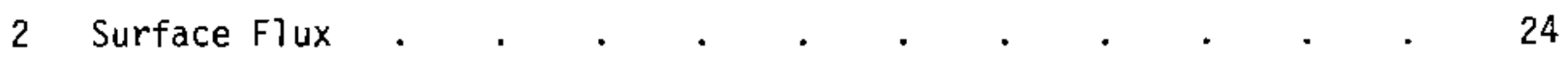

3 Soil Profile Depth Nodes and Initial Conditions for Simulation of the 1979 Climate of Grand Junction, Colorado . . . . 28

4 Layer Characteristics A+ Clay/Rock Layer Case . . . . 29

5 Days Required for Plant Roots to Reach Various Depths . . . 32

6 Water Balance for One Wet Year Followed by Four Dry Years (A+ clay/gravel layer case) . . . . . . . . . 38

7 Layer Characteristics (A- clay/gravel layer case) . . . . 42

8 Water Balance for One Wet Year Followed by One Dry Year (Aclay/gravel layer case) . . . . . . . . . . . 45

9 Layer Characteristics--Discontinuous Cover Case . . . . 47 



\section{NOMENCLATURE}

A An arbitrary coefficient

a Leading coefficient in the diffusion coefficient relationship (typical value: 0.74 )

B An arbitrary coefficient or, the exponent in the diffusion coefficient relationship (typical value: 2.16)

C Concentration of radon gas

c Specific heat

D Diffusion coefficient

E Emanating power (typical value: 0.2 )

G Generation rate per unit volume

$\bar{\jmath}$ Diffusive flux vector

$k$ Themal conductivity

$L \quad$ Thickness of a layer

M Node number

P Volumetric material porosity or void fraction

R Radium content

T Temperature

t Time

$\bar{u} \quad$ Velocity vector

$x \quad$ Horizontal axis

$z \quad$ Vertical axis (typically referenced to bottom of tailings pile)

artuosity

$\bar{\nabla} \quad$ Del operator $\left(\bar{\nabla}=\hat{i} \frac{\partial}{\partial x}+\hat{j} \frac{\partial}{\partial y}+\hat{k} \frac{\partial}{\partial z}\right)$ 
$\lambda \quad$ Decay constant

$\rho \quad$ Density

$\theta \quad$ Volumetric moisture content

Subscripts

a The property is for air

BT The value corresponds to bare tailings

e The property is an effective or bulk value

L Refers to lower material layer

$M \quad$ Node number $M$

$n$ Layer or interface number

$\mathrm{N}$ The top layer or interface

S The value corresponds to the surface

U Refers to upper material layer

Superscripts

- A reference value

m Time index 


\section{INTRODUCTION}

Uranium mill tailings consist of the waste or refuse left after uranium processing. The typical disposal method has been to slurry the tailings into large ponds that eventually dry out and leave a tailings pile. Since the taiiings contain significant quantities of radium, they emit radon gas, which is a decay product of radium. Eecause exposure to radon gas has been linked to lung cancer, concern has been expressed over the health and environmental aspects of open tailings piles. In response to this concern, Pacific Northwest Laboratory (PNL) ${ }^{(a)}$ contracted with the Department of Energy's Uranium Mill Tailings Remedial Action Program (UMTRAP) to develop a capability to model and analyze the fundamental interactions that influence the diffusion of radon gas through uranium mill tailings and cover systems. The purpose of this study is to develop the theoretical basis for modeling radon diffusion and to develop an understanding of the fundamental interactions that influence radon diffusion.

This study develops the theoretical basis for modeling radon diffusion in one, two and three dimensions. The theory has been incorporated into three computer models that are used to analyze several tailings and cover configurations.

This report contains a discussion of the theoretical basis for modeling radon diffusion, a discussion of the computer models used to analyze uranium mill tailings and multilayered cover systems, and presents the results that have been obtained.

(a) Operated by Battelle Memorial Institute. 



\section{CONCLUSIONS AND RECOMMENDATIONS}

This study demonstrates that it is possible to model radon gas flux from bare tailings and covered tailings piles. Analyses can be performed in more than one dimension and can solve both the transient and steady-state problem. The effects of varying soil mojsture content can also be taken into account. The models currently available--RADON1 (1D steady state), RNDI1D (10 transient), and RADMD (multidimensional transient or steady state)--can handle all the cover configurations studied to date. The models are also capable of simulating conditions that are much more complex. The analysis of covered uranium mill tailings using these models indicated the following:

- Radon gas flux can be attenuated more effectively by multilayer systems than by single layers of the same thickness, provided that the multilayer system contains layer sequences having lower air-filled porosity than those found in the single-cover system.

- The influence of varying soil moisture on radon gas flux has been demonstrated. Consequently, care must be taken when designing a cover system to ensure that the design will maintain a high soil moisture content over long periods of time.

- Radon flux, from covered tailings piles similar to those described in this report, will cycle by a factor of two or more in response to climatic variables that cause moisture accumulation and loss from the cover.

- An engineered moisture control barrier system such as the one considered in this report provides an effective method for maintaining a relatively high moisture content and, hence, results in effective attenuation of radon gas flux.

- The attenuation of radon flux through a given cover layer is not influenced by changes in the layers below. The attenuation will be influenced by changes in the layer or in layers lying above.

- The cover layer that is most resistive to the diffusion of radon should be placed at the top of the pile, if maximum radon attenuation is the only consideration. 
- Usua17y, although not always, the maximum radon flux attenuation will be achieved if lower-resistance cover layers are always placed below higherresistance cover layers. (A different ordering scheme may result in slightly greater attenuation of radon flux).

Future studies should make minor modifications to RADMD to allow the simulation of time and spatially varying moisture content in the cover materials. The moisture content values would need to be generated by a multi-dimensional, partially-saturated flow code. A likely candidate for performing the partially saturated flow analysis may be TRUST (Narasimhan and Witherspoon 1977; Key et al. 1981) since it uses a discretization and solution scheme that is similar to RADHD. Other studies may also use the convective transport capabilities of RADMD to investigate the effects that varying barometric pressure may have on the radon flux from tailings piles. 


\section{THEORY}

The following four subsections discuss the theoretical background necessary to perform the analysis of radon diffusion through tailings and multilayer earthen covers. The first subsection discusses the general radon diffusion equation. The next three subsections present important aspects of steady-state and transient one-dimensional modeling of radon diffusion and multidimensional modeling of radon diffusion.

\section{GENERAL RAOON DIFFUSION EQUATION}

The general equation that describes the diffusion of radon gas through a porous medium has been reported eariier by Nelson et al. (1980). Essentially, the equation is a mass balance for the radon gas and can be expressed as follows:

$$
\frac{\partial}{\partial t}[(P-\theta) C]=\bar{\nabla} \cdot D e^{\bar{\nabla} C}-(P-\theta) \lambda C+R \rho_{b} \lambda E
$$

where,

$(P-\theta)$ is the gas-filled pore space in the porous material,

$P$ is the material porosity or void fraction on a volume basis,

$\theta$ is the moisture content on a volume basis,

$C$ is the pore (gas-filled) concentration of radon (typical units: $\left.\mathrm{pCi}-\mathrm{Cm}^{-3}\right)$,

$0_{e}$ is the effective or bulk diffusion coefficient (typical units: $c \mathrm{~m}^{2}-\mathrm{hr} \mathrm{r}^{-1}$,

$\lambda$ is the decay constant for radon (typical units: $\mathrm{hr}^{-1}$ ),

$R$ is the radium $\left({ }^{226} R\right.$ a) content in the porous material (typical units: $\mathrm{pCi-g^{-1 }}$ ), 
$E$ is the emanating power of the material, which is slightly dependent upon the moisture content, particularly at very low moisture contents (see Tanner 1974).

The left term in Equation (1) accounts for the change in radon gas concentration (in the gas-filled pores) with time. The second term takes into account the change in radon concentration due to diffusion. The third term is a sink term that accounts for loss of radon by radioactive decay, and the final term is a source term that accounts for the generation of radon by radioactive decay of radium.

Equation (1) can be further generalized to include convective transport by replacing the time-derivative term (the left-most term) with the material derivative given by

$$
\frac{D}{D t}[(P-\theta) C]=\frac{\partial[(P-\theta) C]}{\partial t}+\bar{u} \cdot \bar{\nabla}[(P-\theta) C]
$$

For this study, however, we have assumed that the velocity field is zero everywhere, leaving Equation (1) as the working equation.

The bulk diffusive flux vector, $\bar{\jmath}$, can be defined based on Fick's law as follows:

$$
\bar{J}=-D_{e} \bar{\nabla} C
$$

A relationship describing the dependence of $D_{e}$ on the air-filled pore space has been developed by Nelson et al. (1980) and is expressed by

$$
D_{e}=a D_{a}^{\circ}(P-\theta)^{B}+D_{w}^{\circ} \alpha \theta
$$

where,

a is an empirically determined coefficient (typical value: 0.740 ), $D_{a}^{\circ}$ is the radon diffusivity in air (typical value: $360 \mathrm{~cm}^{2}-\mathrm{hr}^{-1}$ ), 
$B$ is an empirically determined coefficient (typical value: 2.16),

$D_{W}^{\circ}$ is the radon diffusivity in water (typical value: $0.036 \mathrm{~cm}^{2}-\mathrm{hr}^{-1}$ ), and $\alpha$ is the tortuosity (typical value: 0.66 ).

Equations (1), (2), and (3) provide the framework for modeling diffusion of radon through taitings and cover layers. The following three sections will discuss simplifications that can be made to Equation (1) to allow the simulation of a variety of taijings pile configurations.

STEADY-STATE, ONE-DIMENSIONAL EQUATION AND ANALYTIC SOLUTIONS

Equation (i) can be simplified considerably if we consider only steadystate, one-dimensional diffusion of radon. These simplifications involve the elimination of the time dependent term and the assumption that the material properties $(P-\theta)$ and $D_{e}$ are constant throughout a given layer. The following equation results:

$$
\frac{d^{2} C}{d z^{2}}-\frac{(P-\theta) \lambda C}{D_{e}}+\frac{R p_{b} \lambda E}{D_{e}}=0
$$

The $z$ direction is taken to be the vertical distance from the base of the tailings, (see figure 1 for a description of the notation). The analytic solution to Equation (4) for the nth layer can be written as follows:

$$
C=A_{n} e^{W_{n} z}+B_{n} e^{-W_{n} z}+S_{n} ; z_{n-1} \leq z<z_{n}
$$

and it follows from Equation (2), written in one-dimension, that

$$
u=A_{n}-D_{e} W_{n} e^{W_{n} z}+B_{n} D_{e} W_{n} e^{-W_{n} z} ; \quad z_{n-1} \leq z \leq z_{n}
$$

where 


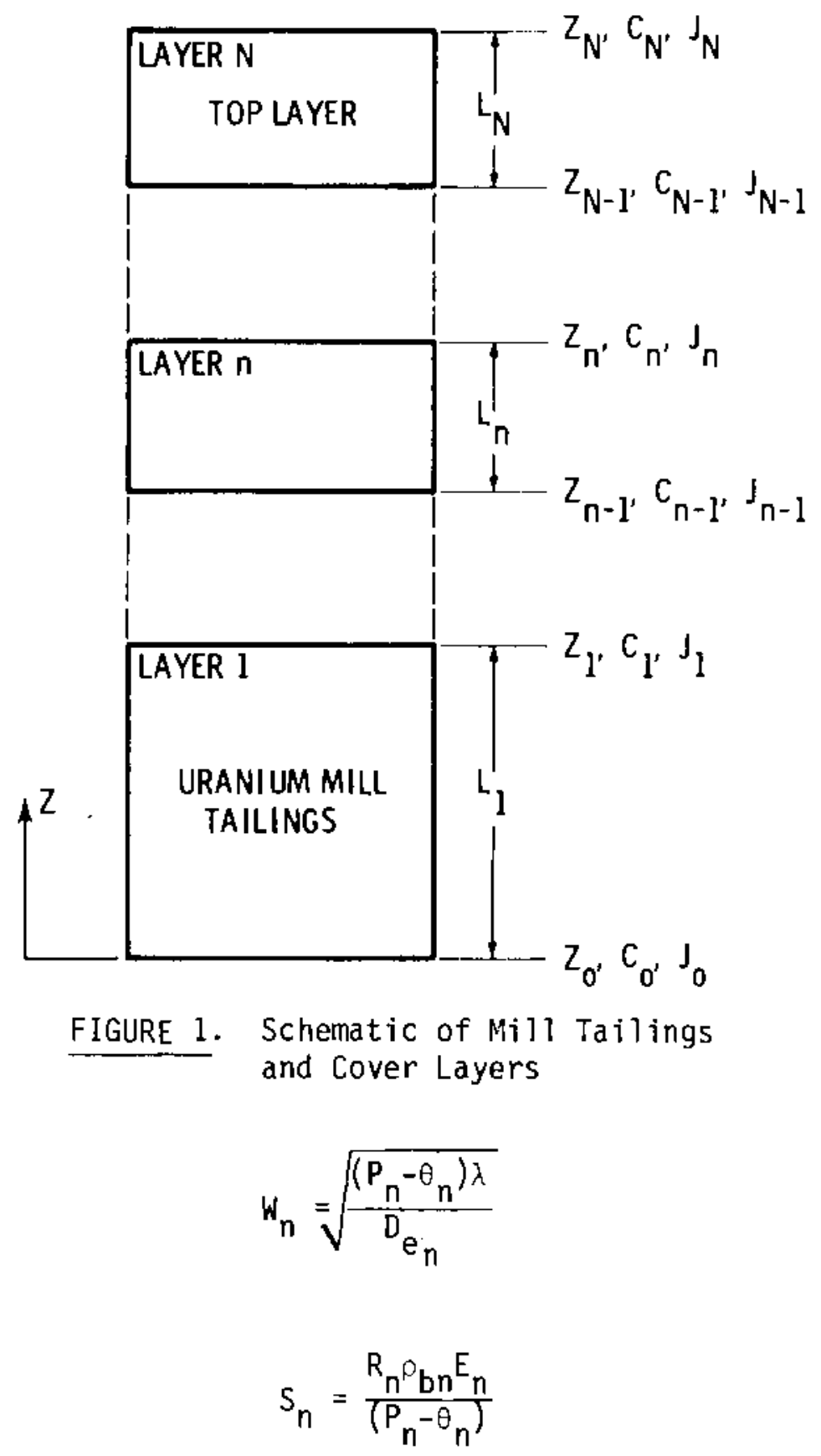

and $A_{n}$ and $B_{n}$ are arbitrary coefficients dependent on the boundary conditions. Note that the subscript, $n$, indicates a parameter that is associated with the nth layer or is associated with the top of the nth layer.

Equations (5) and (6) allow the problem to be solved, in conjunction with the following boundary conditions: 
- flux is continuous across an interface

- concentration is continuous across an interface

- $J_{0}=a$ constant (usually 0 ) or $C_{0}=a$ constant

- $C_{N}=a$ constant (usually 0 ) or $J_{N}=a$ constant

The solution is obtained by solving the following matrix equation:

$$
[K]\{V\}=\{R\}
$$

where,

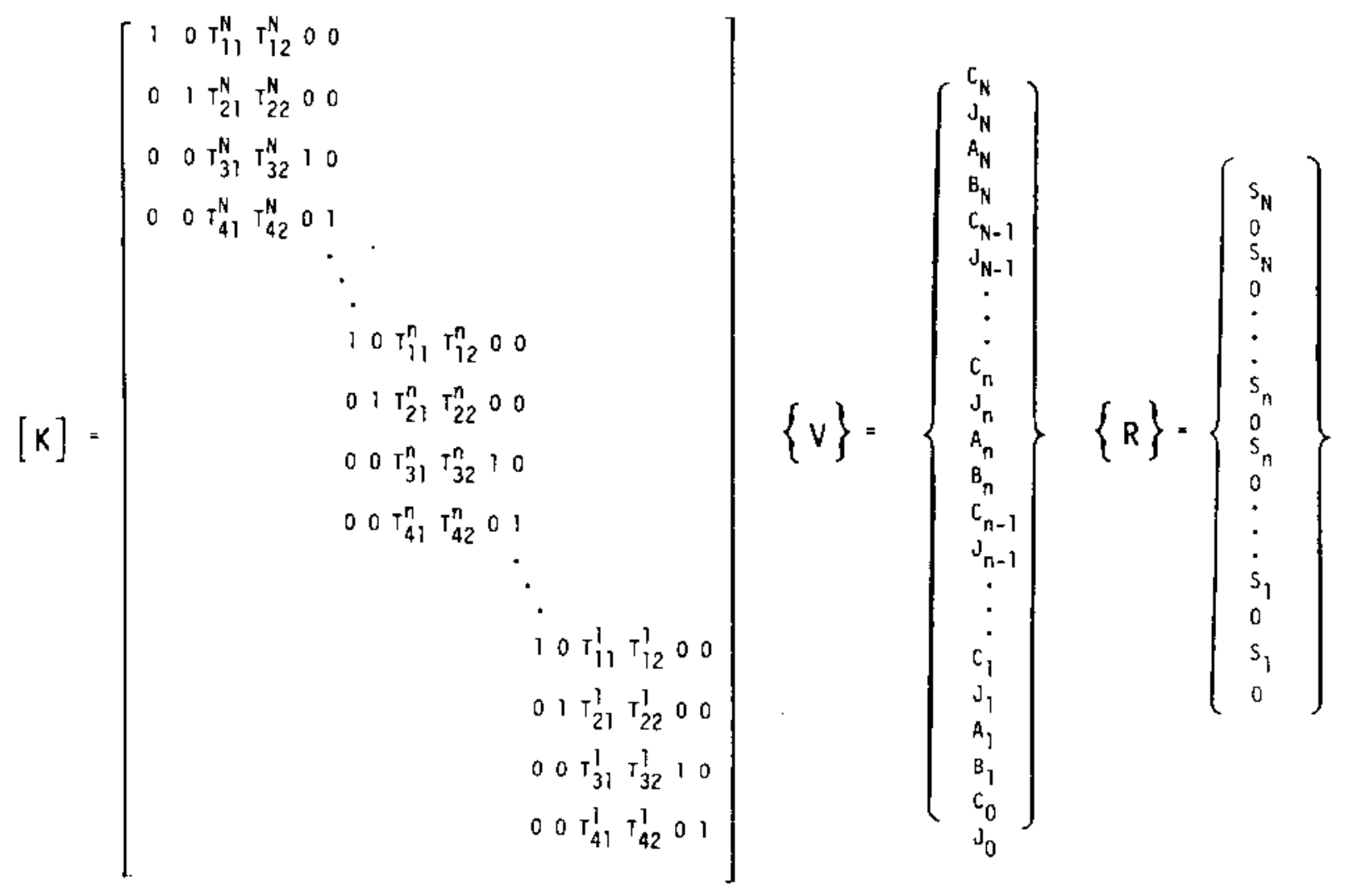


and

$$
\begin{aligned}
& T_{11}^{n}=-e^{W_{n} z_{n}} \quad T_{12}^{n}=-e^{-W_{n} z_{n}} \\
& T_{21}^{n}=D_{e_{n}}{ }_{n} e^{W_{z} z} \quad T_{22}^{n}=-D_{e_{n}} W_{n} e^{-W_{n} z} \\
& T_{3\}}^{n}=-e^{W_{n}^{z} n-1} \quad T_{32}^{n}=-e^{-W_{n} z n-1} \\
& T_{41}^{n}=D_{e_{n}} W_{n} e^{W_{n}^{z} n-1} \quad T_{42}^{n}=-D_{e_{n}} W_{n} e^{-W_{n} z-1}
\end{aligned}
$$

After substituting the bottom and surface boundary conditions, matrix Equation 9 becomes a system of $4 \mathrm{~N}$ simultaneous equations. These equations can be soived by essentially two methods: 1) by algebraic substitution, or 2) by computer. A direct solution by algebraic substitution becomes tedious for more than two layers. Therefore, a computer program called RADON1 has been developed to soive the multilayer, steady-state, radon-diffusion equation in one dimension.

Certain analytic solutions to Equation (4) can be obtained. In the siudies of uranium mill tajlings, it is often of interest to determine the surface flux of radon from a bare tailings pile (i.e., a pile having no cover). This flux, $\mathcal{J}_{B T}$, can be obtained analytically if it is assumed that the radon concentration at the surface of the tailings is zero $\left(C_{N}=0\right)$, and that the flux into the bottom of the tailings is zero $\left(J_{0}=0\right)$. The following equation results:

$$
\mathrm{J}_{\mathrm{BT}}=S_{1} \mathrm{D}_{\mathrm{e} 1} \mathrm{~W}_{1} \tanh \left(\mathrm{W}_{1} \mathrm{~L}_{1}\right)
$$

Using the same boundary conditions, it is also possible to obtain the following relationship for the concentration profile in the bare tailings:

$$
C=S_{1}\left[1-\frac{\cosh w_{1} z}{\cosh \left[w_{1}\left(z_{1}-z\right)\right]}\right] ; z_{0} \leq z \leq z_{1}
$$

Another parameter of interest is the surface flux from a two-layer system (one tailings layer with one cover layer). If the previous boundary conditions 
are assumed, and there is no radium in the upper layer, it can be readily shown that the surface $f 7 u x, J_{2}$, is given by

$$
\frac{\mathrm{J}_{2}}{\mathrm{~J}_{\mathrm{BT}}}=\frac{1}{\cosh \left[\mathrm{w}_{2}\left(z_{2}-z_{1}\right)\right]\left\{\frac{\mathrm{D}_{\mathrm{e} 1^{w_{1}}}}{\mathrm{D}_{\mathrm{e} 2^{w_{2}}}} \tanh \left[\mathrm{w}_{1}\left(z_{1}-z_{0}\right)\right] \tanh \left[w_{2}\left(z_{2}-z_{1}\right)\right]+1\right\}}
$$

with $\mathrm{J}_{\mathrm{BT}}$ computed by Equation (11). It can also be shown that the radon gas flux attenuation through the top cover of a multilayer system is given by

$$
\frac{\mathrm{J}_{N}}{\mathrm{~J}_{N-1}}=\frac{1}{\cosh \left[W_{N}\left(z_{N}-z_{N-1}\right)\right]}
$$

as long as the top layer does not contain radium $\left(R_{N}=0\right)$, and as long as the same boundary conditions used to develop Equations (11), (12) and (13) are assumed. The four analytic solutions (Equations 11, 12, 13 and 14) provide a starting point for the analysis of multilayered cover systems. They also can be used as valuable checks that the numerical solutions are correct. These analytical solutions have been compared with those of Roger et al. 1981. The calculated exit fluxes of radon from each layer of a six-layer test case were compared using both codes, and the results were found to differ by less than $1.4 \%$.

TRANSIENT, ONE-DIHENSIONAL EQUATION

The diffusion boundary value problem, for which Equations (1) and (2) form the basic relationships, is solved numerically using the PNL-developed code, RNDIID, i.e., RadoN DIffusion in $\underline{1}$ Dimension. The solution is obtained by using finite differences with a fully implicit time difference scheme.

The mathematical model consists of $N$ layers of (possibly) distinct materials. Let $n$ denote a layer index, $n=1,2, \ldots, N$. The concentration will be computed at $\|_{n}$ uniformly spaced points or nodes within layer $n$. The first point is at the bottom boundary of layer $n$, and the $1 n$th point is located at 
top node of layer $n$ is located at the top boundary, and the first node of layer $n+1$ is located at the same point, i.e., at the bottom boundary of layer $n+1$ (Figure 2).

Naterial layer $n$ is partitioned into $\|_{n}$ segments. Of these segments, $i_{n}-2$ have equal lengths. The first and last segments are each only half as long as the others. To avoid notational difficulties, we drop the material index, $n$, unless it is essential for clarity. The values of $c_{i}$ are defined at the top and bottom of the layer and at the center of each of the other segments. Thus, the $C_{i}$ are uniformly spaced within the layer.

The diffusion coefficient, $D_{i}$, is defined at the lower boundary of the $i$ th cell. All other quantities are defined at the same points where the $C_{i}$ 's are defined. We first consider only internal nodes.

The flux through the ith cell lower face is

$$
J_{i}=-\left.D_{i} \frac{\partial C}{\partial z}\right|_{z=z_{i}} \simeq D_{i}\left(C_{i-1}-C_{i}\right) / \Delta z ; i=1,2,3, \ldots M
$$

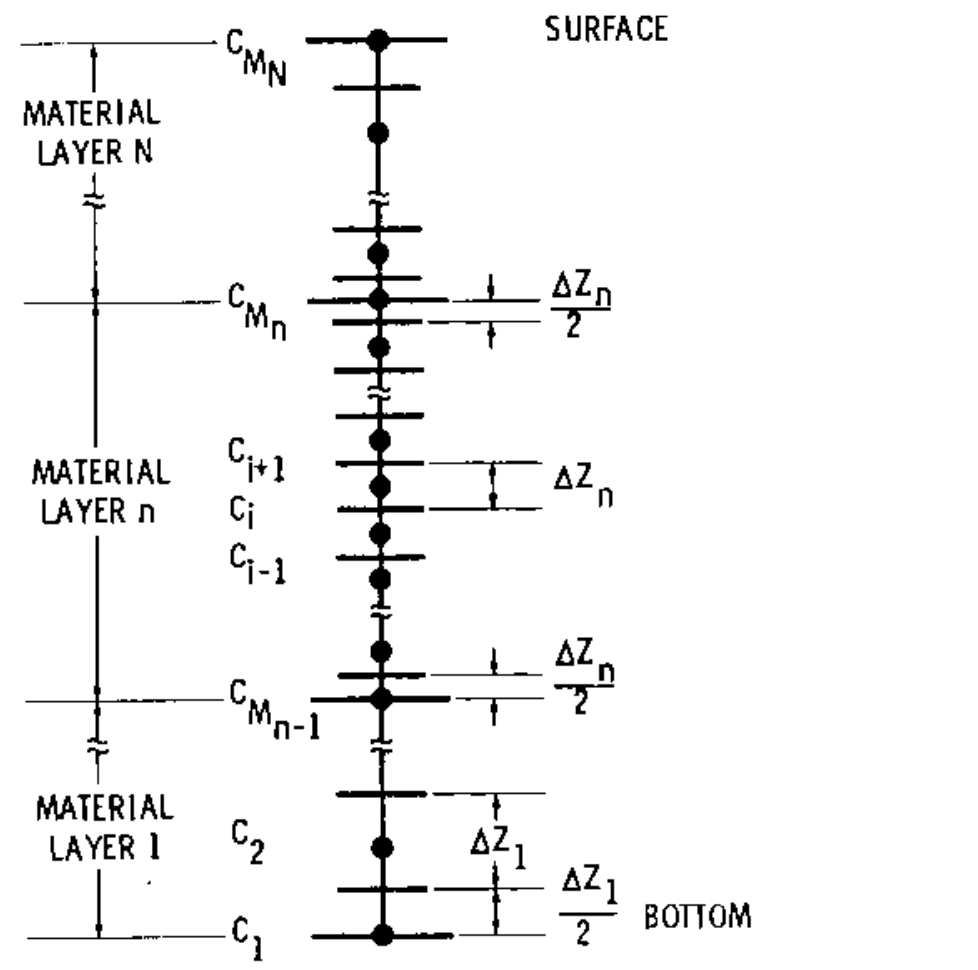

FIGURE 2. Finite Difference Spacing for Material Layers 
The flux through the $i \frac{\mathrm{th}}{\mathrm{th}}$ cell upper face is

$$
J_{i+1}=-\left.D_{i+1} \frac{\partial C}{\partial z}\right|_{z=z_{i+1}} \stackrel{\sim}{-} D_{i+1}\left(C_{i}-C_{i+1}\right) / \Delta z ; i=1,2, \ldots, M-1
$$

Since radon is the product of radioactive decay and is itself radioactive, the change in $C$ due to decay is

$$
\Delta z \rho_{b} \lambda E-\Delta z(p-\theta) \lambda C
$$

where $\mathrm{R}$ is the radium content in the material, $\rho_{b}$ is the material bulk density, $\lambda$ is the radon decay constant, $E$ is the material emanating power, $P$ is the material porosity, and $\theta$ is the volumetric moisture content. The total change in $C$ in the cell with index $i$ during the time period $\Delta t$ is

$$
(P-\theta) \Delta z \frac{\Delta C}{\Delta T} \simeq(P-\theta) \Delta z \frac{C_{i}^{m+1}-C_{i}^{m}}{\Delta t}
$$

where the superscript $m$ is the time index. The conservation of mass for cell $i$ is obtained by combining Equations (15) through (18), dividing through by $\Delta z$ and using a backward difference for the time derivative to yield

$$
\begin{aligned}
(P-\theta)_{i}^{m+1} \frac{C_{i}^{m+1}-C_{i}^{m}}{\Delta t} & =\frac{D_{i+1}^{m+1}}{\Delta z^{2}}\left(C_{j+1}^{m+1}-C_{i}^{m+1}\right)-\frac{D_{i}^{m+1}}{\Delta z^{2}}\left(C_{i}^{m+1}-C_{i-1}^{m+1}\right) \\
& -(P-\theta)_{i}^{m+1} \lambda C_{i}^{m+1}+R \rho_{b} \lambda E_{i}^{m+1}
\end{aligned}
$$

after defining the following variables:

$$
A_{i}^{m+1}=-\frac{D_{i}^{m+1}}{(P-\theta)_{i}^{m+1}} \frac{\Delta t}{\Delta z^{\overline{2}}}
$$




$$
\begin{gathered}
\mathcal{C}_{i}^{m+1}=-\frac{D_{i+1}^{m+1}}{(P-\theta)_{i}^{m+1}} \frac{\Delta t}{\Delta z^{2}} \\
B_{i}^{m+1}=1+\lambda \Delta t-A_{i}^{m+1}-C_{i}^{m+1} \\
D_{i}^{m+1}=C_{i}^{m}+\frac{\Delta t}{(P-\theta)_{i}^{m+1}} R_{i} \rho_{b j} \lambda E_{i}^{m+1}
\end{gathered}
$$

Equation (19) can be rewritten as

$$
A_{i}^{m+1} C_{i-1}^{m+1}+B_{i}^{m+1} C_{i}^{m+1}+C_{i}^{m+1} C_{i+1}^{m-1}=D_{i}^{m+1}
$$

for $i=2,3, \ldots, M-1$.

For the interface node between two adjacent material layers, we require that the flux be continuous at the interface. By introducing the following notation, in which $L$ and $U$ denote the lower and upper material layers, respectively, and $i$ denotes the node index at the interface, we have

$$
-D_{L} \frac{C_{i}^{m+1}-C_{i-1}^{m+1}}{\Delta z_{L}}=-D_{U} \frac{C_{i+1}^{m+1}-C_{i}^{m+1}}{\Delta z_{U}}
$$

By defining

$$
\begin{gathered}
A_{i}^{m+1}=D_{L}^{m+1} / \Delta z_{L} \\
C_{j}^{m+1}=D_{U}^{m+1} / \Delta z_{U} \\
B_{i}^{m+1}=-A_{i}^{m+1}-C_{i}^{m+1}
\end{gathered}
$$




$$
0_{i}^{m+1}=0
$$

then Equation (25) may be expressed in the form of Equation (24).

We now examine the boundary conditions. Two types are permitted at the bottom of material 1 and at the top of material N. The concentration, $\mathrm{C}$, may be specified or the flux, J, may be specified at the boundary.

Consider first the bottom boundary node $i=1$. If $c_{1}$ is specified, then no equation is needed for $i=1$ and, for $i=2$, we have the following modifications to (19) through (23):

$$
\begin{gathered}
A_{2}^{m+1}=0 \\
C_{2}^{m+1}=-\frac{D_{3}^{m+1}}{(P-\theta)_{2}^{m+1}} \frac{\Delta t}{\Delta z^{2}} \\
B_{2}^{m+1}=1+\lambda \Delta t+\frac{D_{2}^{m+1}}{(P-\theta)_{2}^{m+1}} \frac{\Delta t}{\Delta z^{2}}-C_{2}^{m+1} \\
D_{2}^{m+1}=C_{2}^{m}+\frac{\Delta t}{(P-\theta)_{2}^{m+1}} R_{2} P_{b 2}{ }^{\lambda E_{2}^{m+1}}+\frac{D_{2}^{m+1}}{(P-\theta)_{2}^{m+1}} \frac{\Delta t}{\Delta z^{2}} C_{1}^{m+1}
\end{gathered}
$$

If the flux, $\mathrm{J}^{\mathrm{m}+1}$, is specified at the first node, $i=1$, then, using a forward difference in $z$ results in

$$
J_{1}^{m+1}=-D_{1}^{m+1} \frac{c_{2}^{m+1}-c_{1}^{m+1}}{\Delta z}
$$

This equation can be rewritten in the form of Equation (24) by letting 


$$
\begin{gathered}
A_{1}^{m+1}=0 \\
C_{1}^{m+1}=-0_{1}^{m+1} / \Delta z \\
B_{1}^{m+1}=-C_{1}^{m+1} \\
D_{1}^{m+1}=J_{1}^{m+1}
\end{gathered}
$$

Consider the node at the earth's surface, $i=\|_{N}$. If $C_{j}$ is specified, then no equation is needed, but the equation for $i=N_{N}-1$ is modified as follows:

$$
\begin{gathered}
A_{i}^{m+1}=-\frac{D_{i}^{m+1}}{(P-\theta)_{i}^{m+1}} \frac{\Delta t}{\Delta z^{2}} \\
C_{i}^{m+1}=0 \\
B_{i}^{m+1}=1+\lambda \Delta t-A_{i}^{m+1}+\frac{D_{j+1}^{m+1}}{(P-\theta)_{i}^{m+1}} \frac{\Delta t}{\Delta z^{2}} \\
D_{i}^{m+1}=C_{i}^{m}+\frac{\Delta t}{(P-\theta)_{i}^{m+1}} R_{i} \rho_{b i} \lambda E_{i}^{m+1}+\frac{D_{j+1}^{m+1}}{(P-\theta)_{i}^{m+1}} \frac{\Delta t}{\Delta z^{2}} C_{i+1}^{m+1}
\end{gathered}
$$

If the flux is specified at the surface then, using a backwards difference in $z$, we have for $i=M_{N}$

$$
J_{i}^{m+1}=-D_{i}^{m+1} \frac{c_{i}^{m+1}-c_{i-1}^{m+1}}{\Delta t}
$$


which can be written like Equation $\{24\}$ by letting

$$
\begin{gathered}
A_{i}^{m+1}=D_{i}^{m+1} / \Delta z \\
C_{i}^{m+1}=0 \\
B_{i}^{m+1}=-A_{i}^{m+1} \\
D_{i}^{m+1}=J_{i}^{m+1}
\end{gathered}
$$

Using the above equations, we find that the entire system of equations written over all material layers can be expressed as

$$
A C=D
$$

where $A$ is a tridiagonal matrix whose subdiagonal entries are the $A_{i}^{m+1}$, whose main diagonal entries are the $B_{\dot{i}}^{m+1}$, and whose superdiagonal entries are the $C_{i}^{m+1}$. Vector $D$ has the $D_{i}^{m+1}$ for $i$ ts components. The solution vector, $C$, has $\mathrm{C}_{i}^{\mathrm{m}+1}$ as its components. Equation (48) is then solved by the Thomas algorithm (Ames 1977).

The accuracy of the numerical solution could be increased somewhat by using higher order difference approximations for the flux conditions at layer boundaries. This will entail a more complicated matrix, A, in Equation (48). For example, if a three-point difference approximation were used in the flux equation, the matrix, $A$, would be pentadiagonal (i.e., matrix $A$ would have five diagonals instead of three). Algorithms exist for solving such systems (e.g., von Rosenberg 1969).

\section{MULTIDIMENS IONAL ANALYSIS}

To develop a multidimensional analysis capability for radon diffusion, we have used the mathematical similarity between heat conduction and gaseous 
diffusion processes. The equations describing each process are mathematically identical except for the decay term that arises in the radon diffusion equation. The general radon diffusion equation (excluding convection) is given by Equation (1)

$$
\frac{\partial}{\partial t}[(P-\theta) C]=\bar{\nabla} \cdot D_{e} \bar{\nabla} C-(P-\theta) \lambda C+R p_{b} \lambda E
$$

In comparison, the general heat conduction equation (excluding convection) is given by

$$
\rho c \frac{\partial T}{\partial t}=\bar{\nabla} \cdot k \vec{\nabla} T+G
$$

where
$\rho$ is mass density,
$c$ is specific heat,
$T$ is temperature in absolute units,
$t$ is time,
$k$ is thermal conductivity, and
$G$ is heat generation per unit volume.

Now, if it is assumed that the gas-filled porosity $(P-\theta)$ is constant or nearly constant (at least during a given time step), Equation (1) can be rewritten as:

$$
(P-\theta) \frac{\partial C}{\partial t}=\bar{\nabla} \cdot D e^{\bar{\nabla} C}-(P-\theta) \lambda C+R \rho_{b} \lambda E
$$

which is identical in form to Equation (49) with the addition of the decay term, $-(P-\theta) \lambda C$. The source term, $R p_{b} \lambda E$, is analogous to the heat generation rate, $G$.

The multidimensional modeling capability is based on the solution scheme employed in the TRUMP computer code (Edwards 1972), which solves Equation (49) 
in one, two, or three dimensions and in cartesian, cylindrical, or spherical coordinates. The new code, RADMD (for RAdioactive Diffusion in lilultidimensions), uses the solution scheme employed by TRUMP modified to handle the additional decay term. The numerical formulation is based on an integrated, finite-difference representation of Equation (49). The code can, therefore, handle irregular grids and is not limited to the more traditional rectangular, finite-difference grids. Furthermore, it will be a simple matter to include convective transport if the need arises. 
. 


\section{APPLICATIONS}

STEADY-STATE, ONE-DIMENSIONAL

One parameter that is of particular interest in the study of uranium mill tailings is the flux of the bare tailings (i.e., tailings having no cover layers) expressed as $\mathrm{J}_{\mathrm{BT}}$. This value can be computed directly using Equation (11). A plot of $\mathrm{J}_{B T}$ divided by a measure of the tailings source strength versus the tailings thickness is shown in Figure 3. This plot demonstrates that, even for very porous material, tailings can be treated as if they were infinitely deep if their depth is greater than 4 meters.

The attenuation of the radon flux through the top cover layer for any system that consists of one or more cover layers is given by Equation (14). An interesting feature of Equation (14) is that the ratio of output and input fluxes for the top cover layer is not affected by changes in layers below. That is, the attenuation through layer $\mathrm{N}$ is a function of layer- $\mathrm{N}$ parameters (and the surface concentration boundary condition) only.

Based on an extension of this observation, a hypothesis is proposed regarding the attenuation through any individual cover layer. The hypothesis can be stated as follows:

- The attenuation through the nth layer will not be influenced by changes in the characteristics of lower layers (i.e., layers 1 through $n-1$ ), but will be influenced by changes in the nth layer and layers lying above (i.e., layers $n$ through $N$ ). (This statement assumes that the nth and upper layers do not contain a radon source and that the surface concentration is fixed.)

We have not proven this hypothesis, but numerical experiments performed using RADON1 demonstrate that the hypothes is is correct. Figure 4 is a plot of the attenuation through the clay layer in a four-layer problem (i.e., three cover layers and one tailings layer). The bare tailings flux, $J_{B T}$, curves on Figure 4 indicate the design characteristics required for the clay layer so that a $2 \mathrm{pCi}-\mathrm{m}^{-2}-\mathrm{s}^{-1}$ surface flux will be achieved for the given bare tailings flux. 


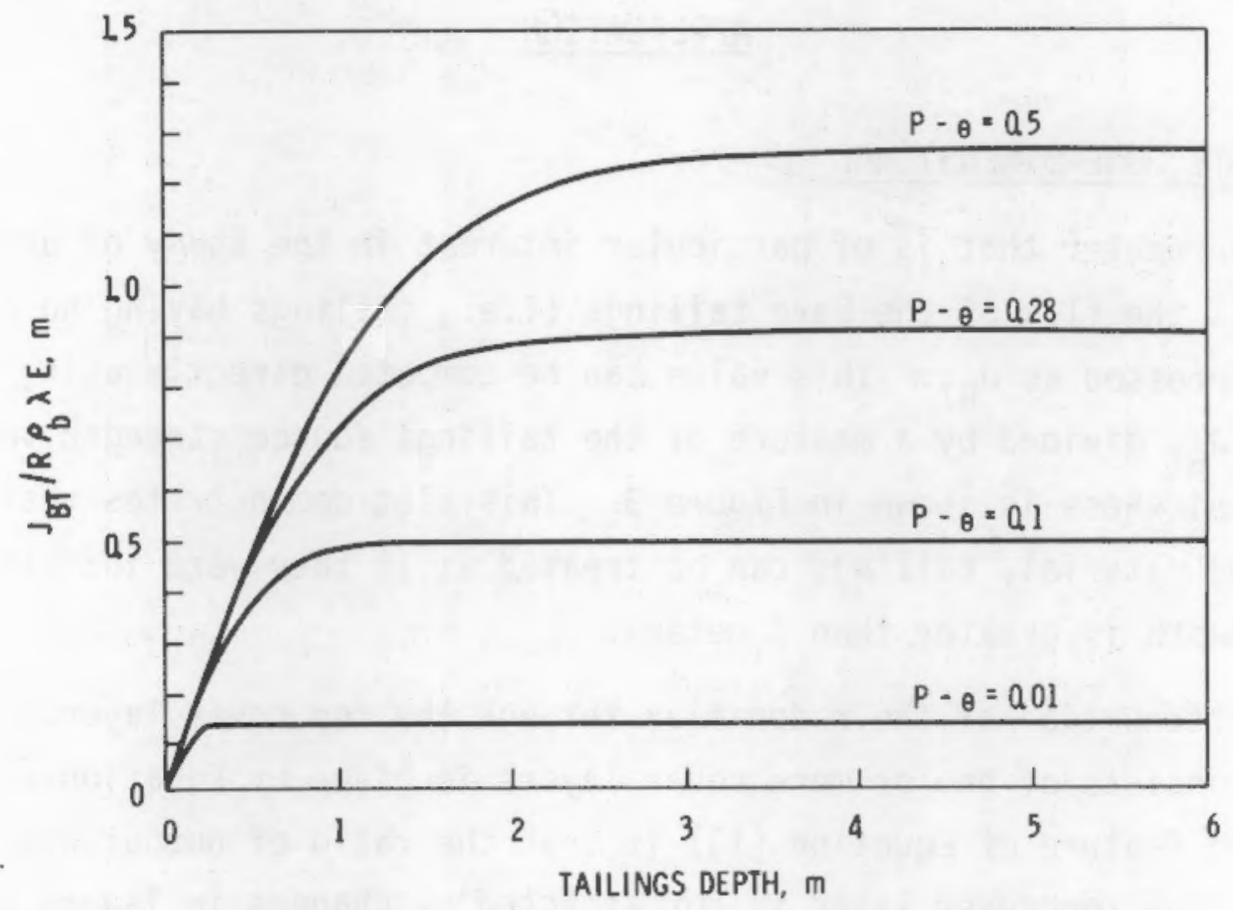

FIGURE 3. Scaled Parameter Evaluation of "Infinite" Tailings

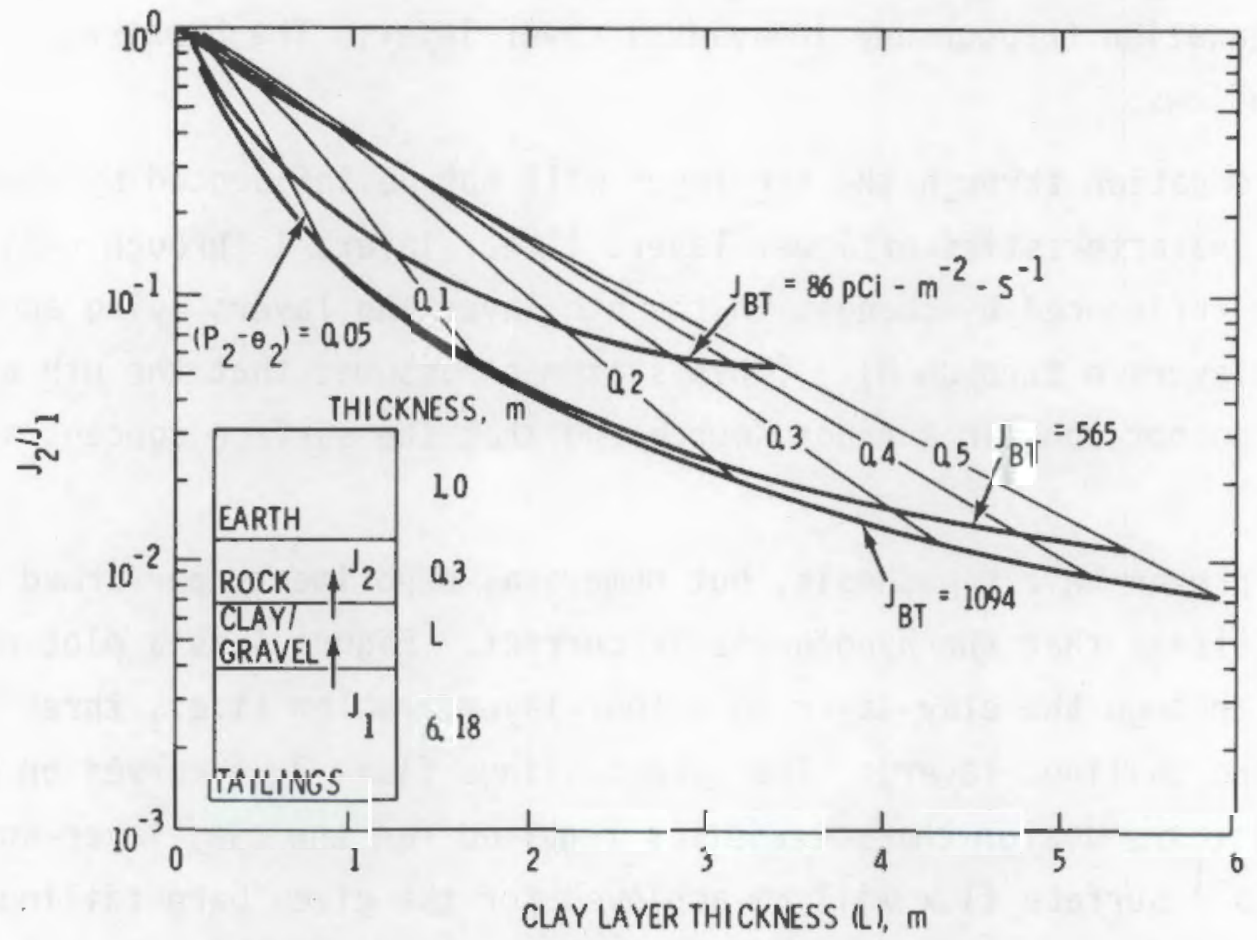

FIGURE 4. Influence of $L_{2},\left(P_{2}-\theta_{2}\right)$ and Tailings Strength on Layer 2 Attenuation 
Note that the shape of the $P-\theta$ curves is the same regardless of the strength of the bare tailings, which indicates that the attenuation through the clay layer is not affected by a change in the lower layer.

To explain why the hypothesis holds true, consider the diffusion of radon through a multilayered cover. If the top layer is made more resistive to the diffusion of radon (e.g., if it is made thicker, given a higher moisture content, or a lower porosity), the diffusion of radon will be slowed down in lower layers. The slowdown occurs because the concentration gradient in lower layers is reduced as a result of the concentration buildup under the more resistive layer. Hence, more radon will decay in a given layer, and the attenuation through each layer will be increased. In a similar manner, if the top layer is made less resistive, the attenuation through all layers will be decreased.

From the previous analysis it is proposed that the layer most resistive to the diffusion of radon should be placed at the top of the pile, if maximum radon attenuation is the only consideration. An obvious generalization of this statement is that the multilayered cover should be designed such that the resistance of a given cover layer is always greater than the resistance of each cover layer below. While this is nomally true, there are certain combinations of layer characteristics, order, and thicknesses for which the surface flux varies slightly from the rule.

To demonstrate these ideas, a numerical experiment has been performed in which all the parameters--except the order of the three cover layers--are fixed. Table 1 shows the layer characteristics. Since the moisture content in the three cover layers was fixed at zero, the only difference between Covers $A, B$ and $C$ is their porosity. Hence, the resistance of Cover $A$ is the least, the resistance of Cover $C$ is the highest, and the resistance of Cover $B$ is between $A$ and $C$. The resulting surface flux obtained for all possible cover configurations is presented in Table 2. These results demonstrate that, to achieve the maximum reduction in the surface flux, it is desirable to have the layer with the highest resistance at the top. The more general statement that the resistance of a given cover layer should be greater than the resistance of each cover 
TABLE 1. Layer Characteristics

\begin{tabular}{|c|c|c|c|c|}
\hline Layer & $\begin{array}{l}\text { Thickness } \\
\text { (m) }\end{array}$ & $\begin{array}{c}P-\theta \\
\left(m^{3}-m^{-3}\right) \\
\end{array}$ & $\begin{array}{c}R \\
\left(p\left(i-g^{-1}\right)\right.\end{array}$ & $\left(g, m^{-}-3\right)$ \\
\hline A & 2.0 & 0.459 & 0 & $1.46 \mathrm{E} 6$ \\
\hline B & 2.0 & 0.370 & 0 & $1.70 \mathrm{E} 6$ \\
\hline C & 2.0 & 0.259 & 0. & $2.00 \mathrm{E} 6$ \\
\hline Tailings & 6.18 & 0.354 & 1600 & $1.23 \mathrm{E} 6$ \\
\hline
\end{tabular}

TABLE 2. Surface Flux

\begin{tabular}{|c|c|c|}
\hline Case & $\begin{array}{c}\text { Cover } \\
\text { Conf iguration } \\
\text { (Top } \rightarrow \text { Bottom) }\end{array}$ & $\begin{array}{c}\text { Surface } \\
\text { Flyx } \\
\left(\mathrm{pci}-\mathrm{m}^{-2}-\mathrm{s}^{-1}\right)\end{array}$ \\
\hline 1 & $C / A / B$ & 1.637 \\
\hline 2 & $C / B / A$ & 1.697 \\
\hline 3 & $B / C / A$ & 2.058 \\
\hline 4 & $B / A / C$ & 2. 108 \\
\hline 5 & $A / C / B$ & 2.460 \\
\hline 6 & $A / B / C$ & 2.617 \\
\hline
\end{tabular}

layer below is generally upheld by the results in Table 2. A small departure from the rule is seen in the reversal of cases 1 and 2. The rule would have predicted that Case 2 would yield the lowest surface flux, while Case 2 actualiy yields only a slightly lower (3.5\%) surface flux.

\section{Design Considerations}

The concepts presented thus far provide guidance for doing initial designs of multilayered uranium mill tailings covers. The designer should keep in mind the following guidelines:

- The radon attenuation through the $n$th layer is not influenced by changes in the characteristics of lower layers, but is influenced by changes in the nth or upper layers.

- The most resistive layer should be the top layer. 
- Usually, it is desirable to place a lower-resistance cover layer below a higher-resistance cover layer.

The order of a given set of cover layers can be defined, based on these considerations, so that the surface radon flux is minimized. This design will have to be modified with consideration given to the

- requirement for plant cover

- root zone depth

- feasibility of construction

- maintenance of moisture in a layer

- prevention of layer degradation (e.g., by burrowing animals).

At this point in the design process, the multilayer, one-dimensional, steady-state diffusion equations will need to be solved to further refine the cover design. The analysis must be based on knowledge of the diffusion properties of the cover, tailings source strength, and cover thicknesses and cannot be approximated from measurements of bare tailings flux.

Figures $5 \mathrm{a}$ through $5 \mathrm{c}$ are plots of the computed surface flux for high, medium and low tailings strengths that result for a typical cover design. The plots have been normalized by dividing the surface flux by the bare tailings flux. The lower end point of the P- $\theta$ curves corresponds to the design characteristics of the second layer, which are necessary to achieve a $2 \mathrm{pCi}-\mathrm{m}^{-2}-\mathrm{s}^{-1}$ surface flux. Curves such as Figure 5 can be easily and rapidly generated for any proposed cover system using RADON1. Once these plots are available, it is a simple matter to select the air-filled porosity, $P-\theta$, and the layer thickness

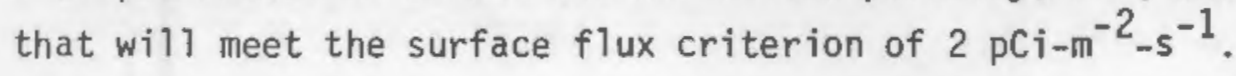

\section{TRANSIENT, ONE-DIMENSIONAL}

Transient analysis of a uranium mill tailings pile becomes important when consideration is given to the effects of changing moisture content. Since the diffusion coefficient, $D_{e}$, is highly dependent on the gas-filled pore volume $(P-\theta)$, changes in the moisture content can significantly affect the radon flux. Therefore, a realistic simulation of a tailings pile should account for all of the factors influencing the moisture content, $\theta$. 


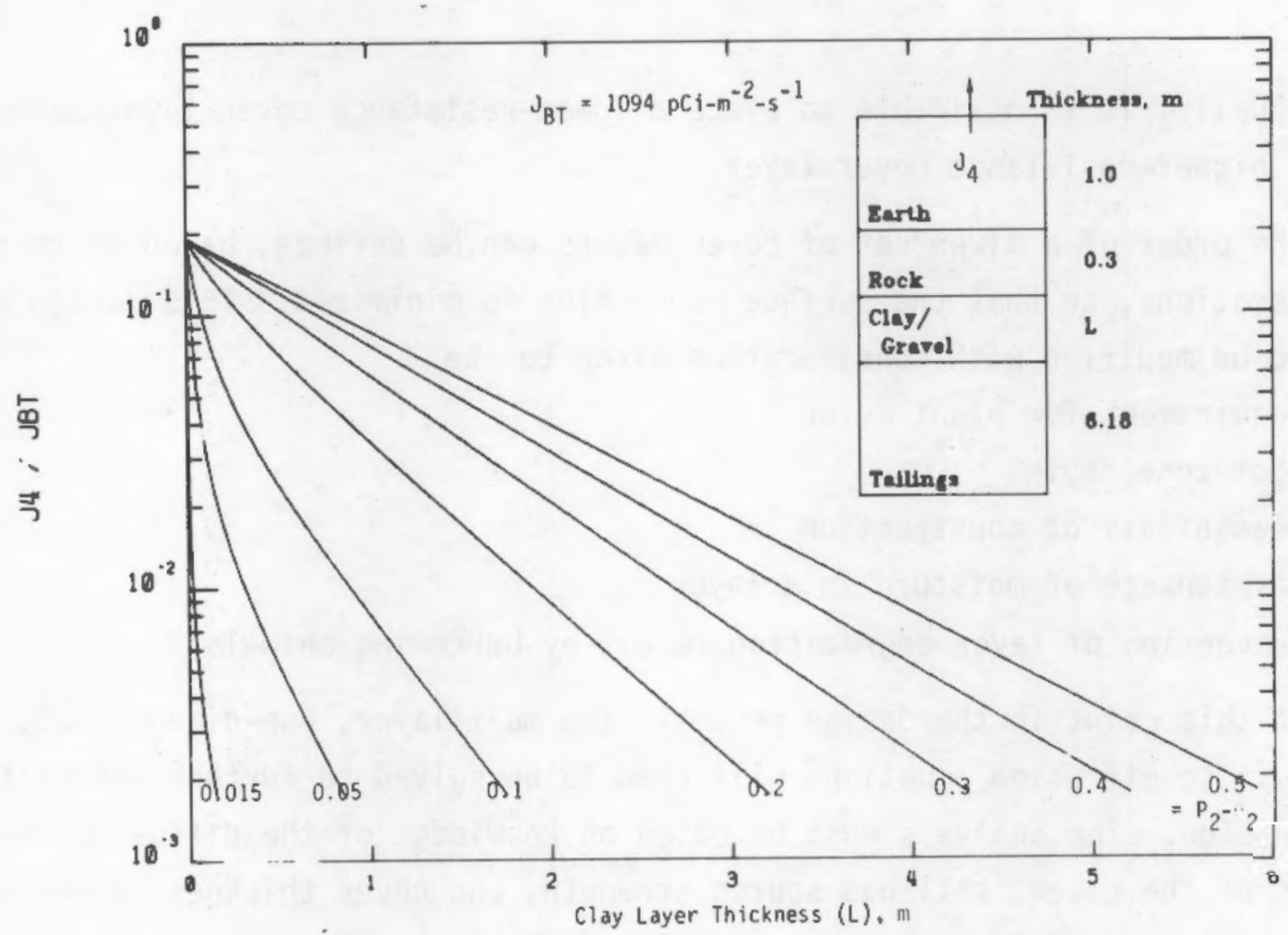

FIGURE 5a. Surface Flux for a High Tailings Strength

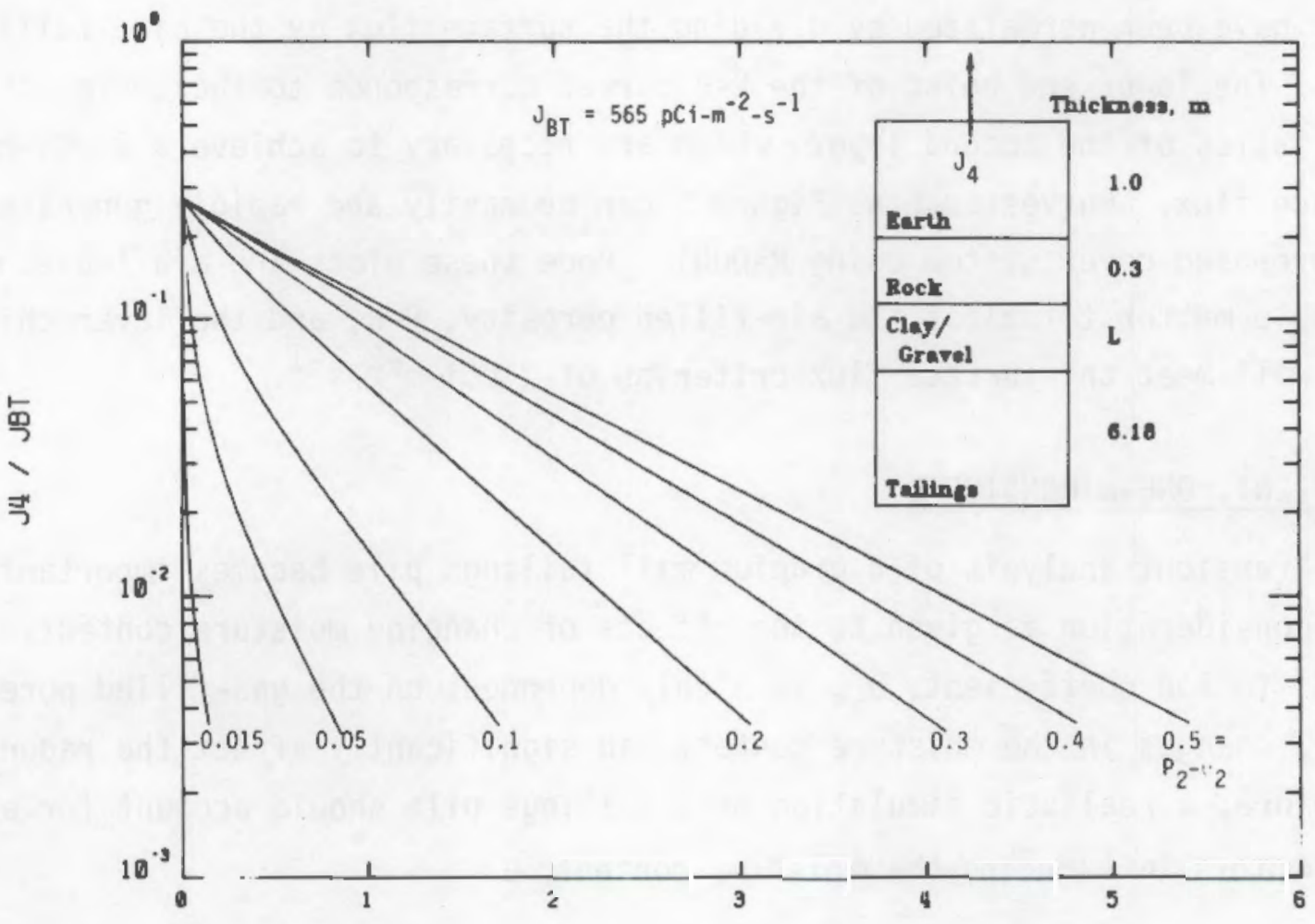

FIGURE 5b. Surface Flux for a Medium Tailings Strength 


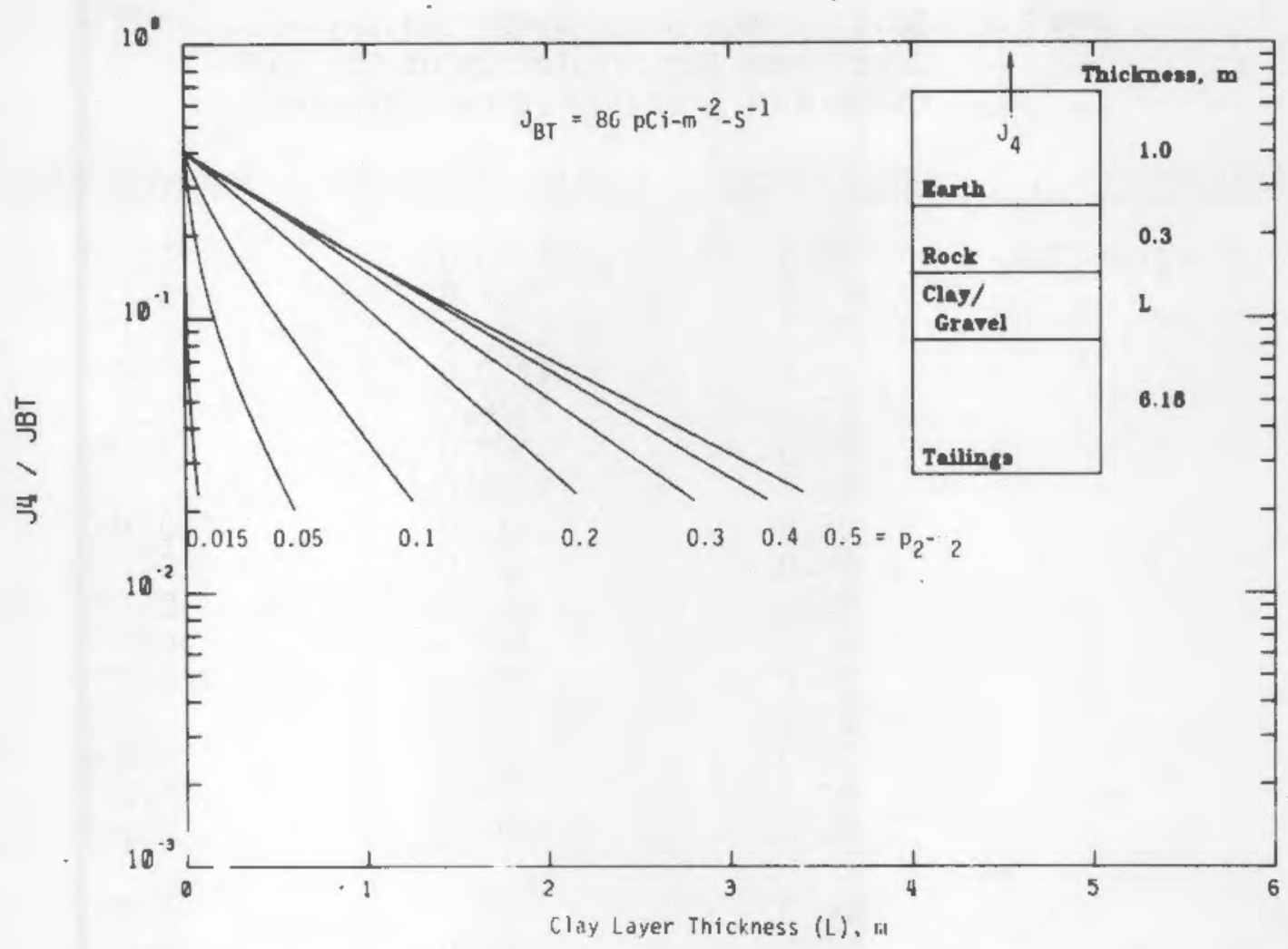

FIGURE 5c. Surface Flux for a Low Tailings Strength

For the following simulations, the partially saturated flow code, UNSATV, developed by Simmons and Gee (1981) has been used. UNSATV is a version of an earlier code, UNSAT, developed by Gupta et al. (1978). The capability to model the effects of water vapor diffusion has been incorporated into UNSATV. The code solves the partially saturated flow equation in one dimension. The important factors considered include water infiltration from precipitation or irrigation, drainage, evaporation, and plant evapotranspiration. For a more detailed description of the code and applications of the code, the reader is referred to the two reference reports.

The test case simulated during this phase of the research is representative of the tailings cover test plots constructed at Grand Junction, Colorado. Table 3 indicates the initial conditions used for the partially saturated flow analysis. The initial conditions shown in Table 3 represent near-equilibrium conditions below the clay/gravel layer to the 763-cm-deep water table. The moisture conditions above the clay/gravel layer are the result of repeated simulations using the recorded climatic conditions and could represent the 
TABLE 3. Soil Profile Oepth Nodes and Initial Conditions for Simulation of the 1979

Climate of Grand Junction, Colorado

Soil Layer Oepth $(\mathrm{cm})$ Suction Head $(\mathrm{cm})$ Water Content

\begin{tabular}{|c|c|c|c|}
\hline Grand Junction $\mathrm{Cl}$ ay & $\begin{array}{r}0.0 \\
2.5 \\
5.0 \\
7.5 \\
10.0 \\
15.0 \\
20.0 \\
25.0 \\
30.0 \\
35.0 \\
40.0 \\
50.0 \\
60.0 \\
70.0 \\
80.0 \\
99.0\end{array}$ & $\begin{array}{r}1450.0 \\
3167.0 \\
1293.0 \\
1230.0 \\
1176.0 \\
1090.0 \\
1025.0 \\
975.0 \\
935.0 \\
902.0 \\
874.0 \\
830.0 \\
796.0 \\
768.0 \\
746.0 \\
709.0\end{array}$ & $\begin{array}{l}0.170 \\
0.172 \\
0.175 \\
0.177 \\
0.179 \\
0.183 \\
0.187 \\
0.190 \\
0.192 \\
0.195 \\
0.197 \\
0.200 \\
0.203 \\
0.206 \\
0.208 \\
0.212\end{array}$ \\
\hline Gravel & $\begin{array}{l}100.0 \\
110.0 \\
120.0 \\
129.0\end{array}$ & $\begin{array}{l}709.0 \\
709.0 \\
709.0 \\
709.0\end{array}$ & $\begin{array}{l}0.008 \\
0.008 \\
0.008 \\
0.008\end{array}$ \\
\hline A+ Clay/Gravel Mix & $\begin{array}{l}130.0 \\
132.0 \\
135.0 \\
140.0 \\
142.0 \\
144.0\end{array}$ & $\begin{array}{l}600.0 \\
600.0 \\
600.0 \\
600.0 \\
600.0 \\
600.0\end{array}$ & $\begin{array}{l}0.259 \\
0.259 \\
0.259 \\
0.259 \\
0.259 \\
0.259\end{array}$ \\
\hline Medium Tailings & $\begin{array}{l}145.0 \\
150.0 \\
160.0 \\
180.0 \\
200.0 \\
250.0 \\
300.0 \\
400.0 \\
500.0 \\
600.0 \\
650.0 \\
700.0 \\
750.0 \\
755.0 \\
760.0 \\
763.0\end{array}$ & $\begin{array}{r}651.0 \\
646.0 \\
629.0 \\
612.0 \\
590.0 \\
524.0 \\
467.0 \\
365.0 \\
265.0 \\
165.0 \\
155.0 \\
65.0 \\
15.0 \\
10.0 \\
5.0 \\
2.0\end{array}$ & $\begin{array}{l}0.141 \\
0.141 \\
0.142 \\
0.144 \\
0.145 \\
0.150 \\
0.155 \\
0.167 \\
0.185 \\
0.214 \\
0.238 \\
0.278 \\
0.370 \\
0.384 \\
0.399 \\
0.408\end{array}$ \\
\hline
\end{tabular}

TOTAL INITIAL MOISTURE STORAGE $145.859 \mathrm{~cm}$ 
initial conditions from a long-term climatic history. The clay/gravel layer moisture content is initially at a nearly saturated state. Table 4 summarizes the layer characteristics used for the radon diffusion simulation. The soilwater characteristics reported by Simmons and Gee (1981) for the Grand Junction clay, rock, and tailings layers have been used for the partially saturated flow simulation. The soil-water characteristics for the A+ clay/gravel mix are represented by the curves shown in Figures $6 \mathrm{a}$ and $6 \mathrm{~b}$.

TABLE 4. Layer Characteristics for At Clay/Rock Layer Case

\begin{tabular}{|c|c|c|c|c|c|}
\hline Layer & $\begin{array}{l}\text { Thickness } \\
(\mathrm{cm}) \\
\end{array}$ & Material & $\begin{array}{l}\text { Porosity } \\
\left(\mathrm{cm}^{3}-\mathrm{cm}^{-3}\right)\end{array}$ & $\begin{array}{l}\text { Density } \\
\left(\mathrm{g}-\mathrm{cm}^{-3}\right) \\
\end{array}$ & $\begin{array}{l}\text { Radium } \\
\text { Content } \\
\left(p C i-g^{-1}\right)\end{array}$ \\
\hline 4 & 100 & $\begin{array}{l}\text { Overburden (Grand } \\
\text { Junction clay) }\end{array}$ & 0.468 & 1.37 & 0 \\
\hline 3 & 30 & Clean rock & 0.320 & 1.80 & 0 \\
\hline 2. & 15 & Clay/gravel mix $(A+)$ & 0.270 & 1.97 & 0 \\
\hline 1 & 618 & Medium tailings & D. 458 & 1.47 & 1600 \\
\hline
\end{tabular}

The moisture simulation assumes a plant cover crop consisting of cheatgrass. During the active growing season, the cheatgrass roots can extract moisture from the covers. Table 5 lists the time required for the roots to reach a given depth during the growing season. Plant growth began on day 120. The root zone moisture extraction has been handled in the same manner described by Simmons and Gee (1981).

Climatic parameters were obtained from monthly summaries of local climatological data for Grand Junction, Colorado, published by the U.S. Department of Commerce, National $\mathrm{Cl}$ imatic Center, Asheville, NC. The data from the summaries for the years 1976 and 1979 were provided in the following units: hourly precipitation (inches); temperature $\left({ }^{\circ} \mathrm{F}\right)$ in terms of daily maximum, minimum, average, and average dew point temperature; average wind speed (m.p.h.); percent of possible sunshine and sky cover in tenths; and maximum and minimum relative humidity. Hourly precipitation determined the water infiltration rate for the modeling. Other climatic parameters were used to estimate potential evapotranspiration on a daily basis. 


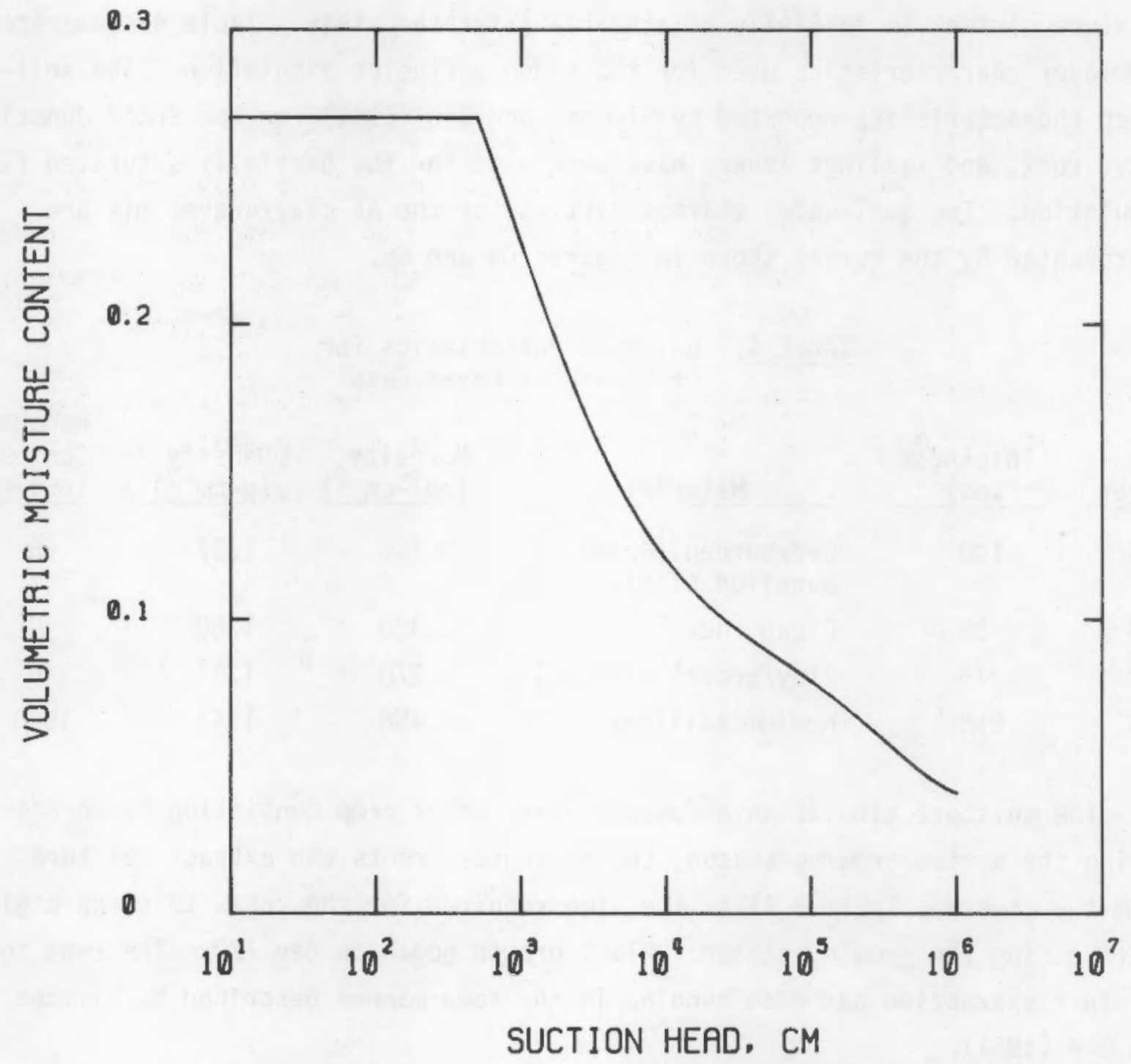

FIGURE 6a. A+ Clay/Gravel Mix Soil-Water Characteristic, Moisture Content Versus Suction Head

Starting with the initial conditions shown in Table 3, UNSATV was run for one year using the 1979-climate data (wettest year on record). This simulation was then followed by four years using repeated 1976-climatic data (driest year on record). These simulations, therefore, are representative of a high rainfall year followed by a protracted dry spell.

Figures 7 a through $7 e$ are plots of the moisture content distributions for selected days from each of the five years simulated. The important feature to 


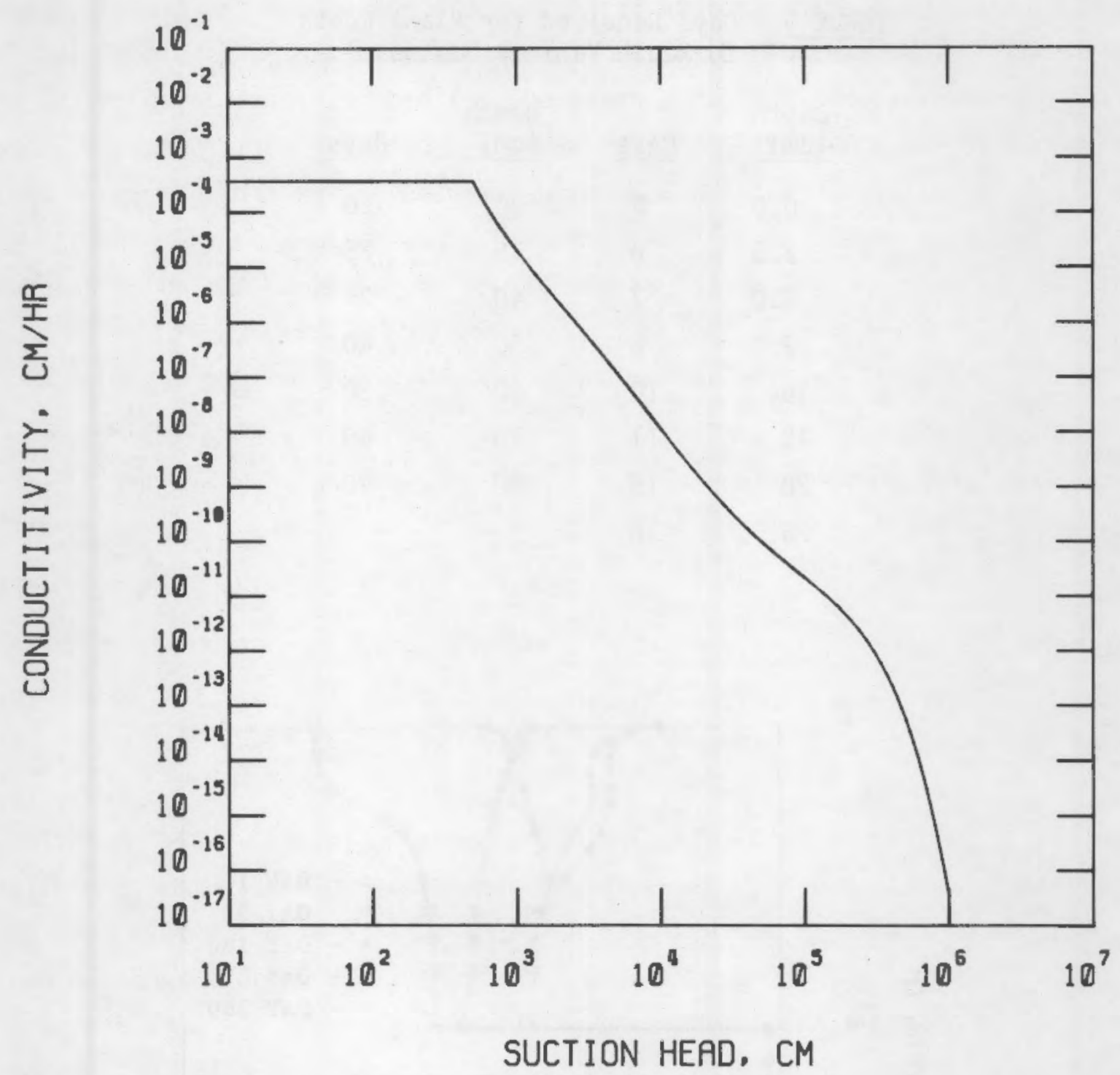

FIGURE 6b. A+ Clay/Gravel Mix Soil Water Characteristic, Conductivity Versus Suction Head

note is that, although the moisture content in the surface layer varies dramatically, the lower layers exhibit very little change in moisture content. To better illustrate this, the moisture storage in the top layer and in the clay/ gravel layer has been computed and plotted. Figures $8 \mathrm{a}$ through $8 \mathrm{e}$ are plots of the total moisture storage in the top cover layer, and Figure 9 is a plot of the moisture in the clay/gravel layer during the four dry years. The moisture storage in the top layer illustrates the seasonal cycle of moisture gain 
TABLE 5. Days Required for Plant Roots to Reach Various Depths

\begin{tabular}{|c|c|c|c|}
\hline $\begin{array}{l}\text { Depth } \\
(\mathrm{cm})\end{array}$ & Days & $\begin{array}{l}\text { Depth } \\
(\mathrm{cm})\end{array}$ & Days \\
\hline 0.0 & 5 & 30 & 20 \\
\hline 2.5 & 6 & 35 & 25 \\
\hline 5.0 & 7 & 40 & 35 \\
\hline 7.5 & 8 & 50 & 40 \\
\hline 10 & 10 & 60 & 50 \\
\hline 15 & 11 & 70 & 60 \\
\hline 20 & 15 & 80 & 70 \\
\hline 25 & 16 & & \\
\hline
\end{tabular}

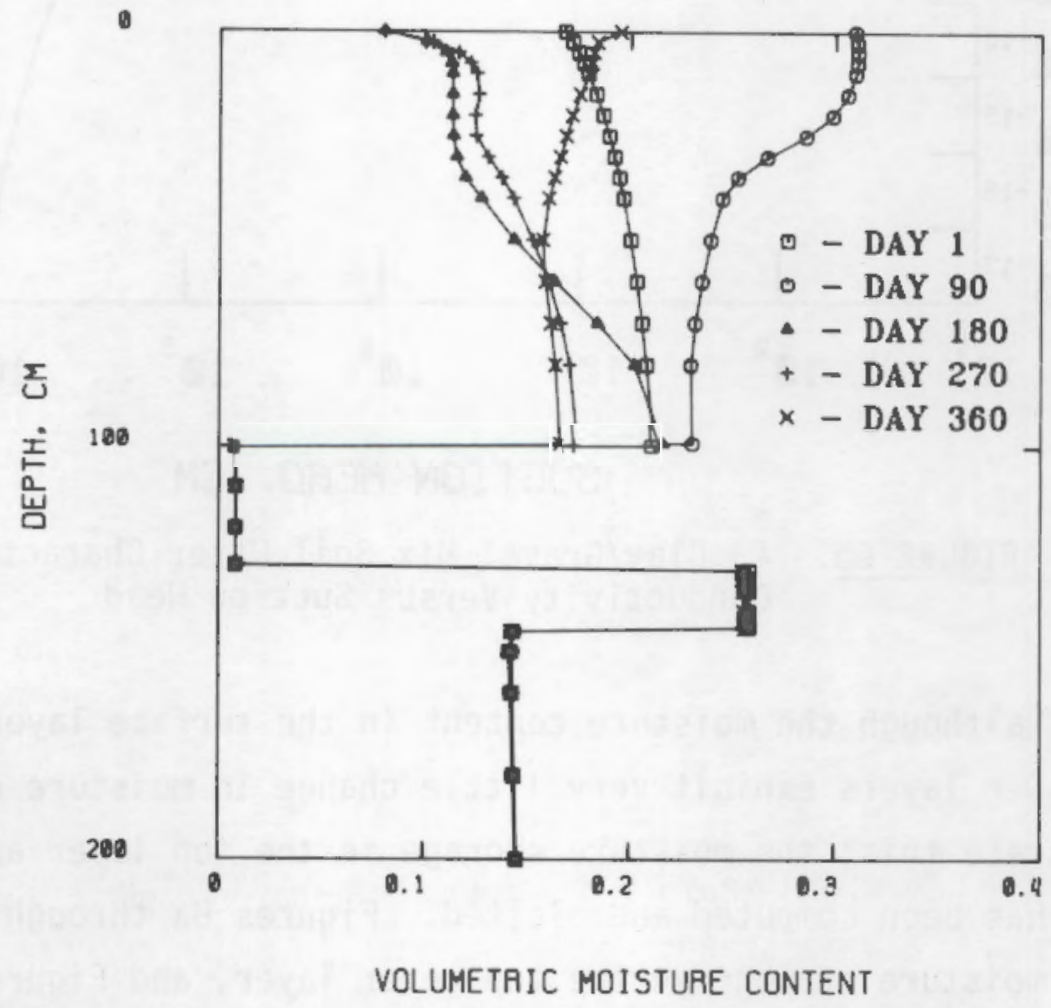

FIGURE 7a. Moisture Content Distribution, Wet Year (1979 Climate Data) - 1st Year 


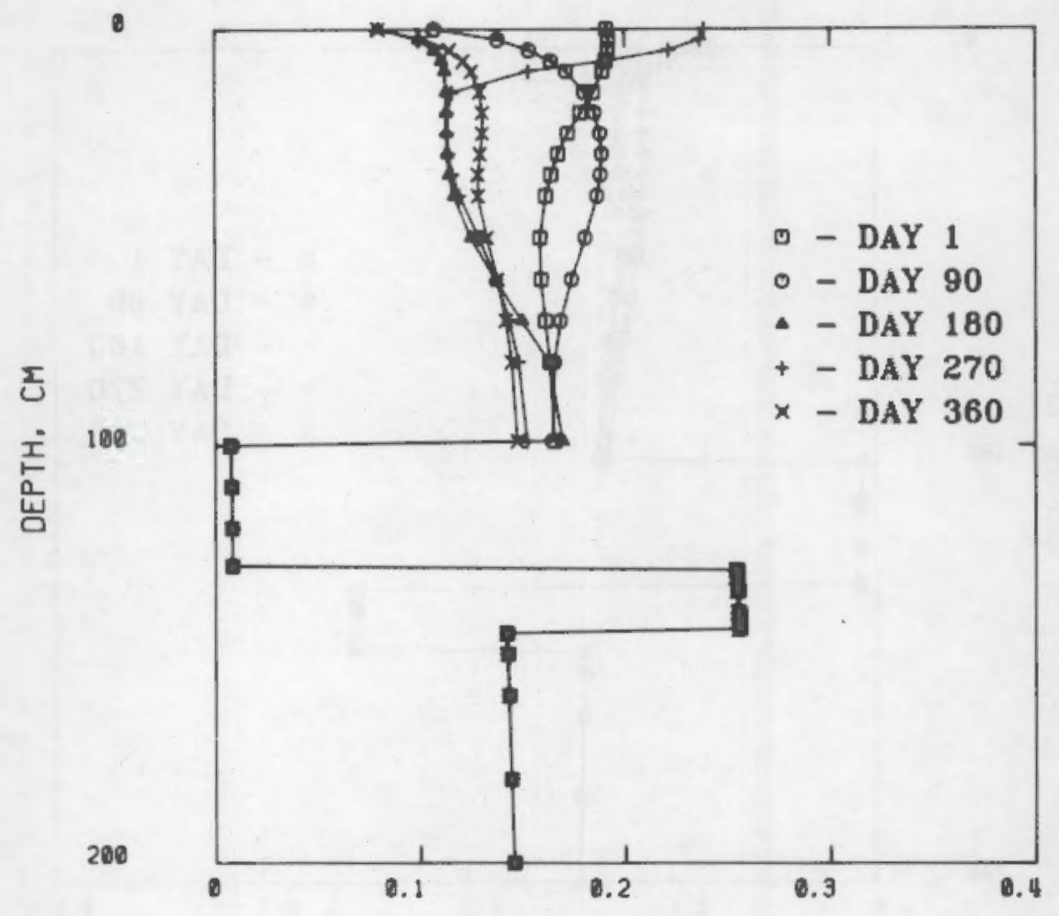

VOLUMETRIC MOISTURE CONTENT

FIGURE 7b. Moisture Content Distribution, Dry Year (1976 Climate Data) - 2nd Year

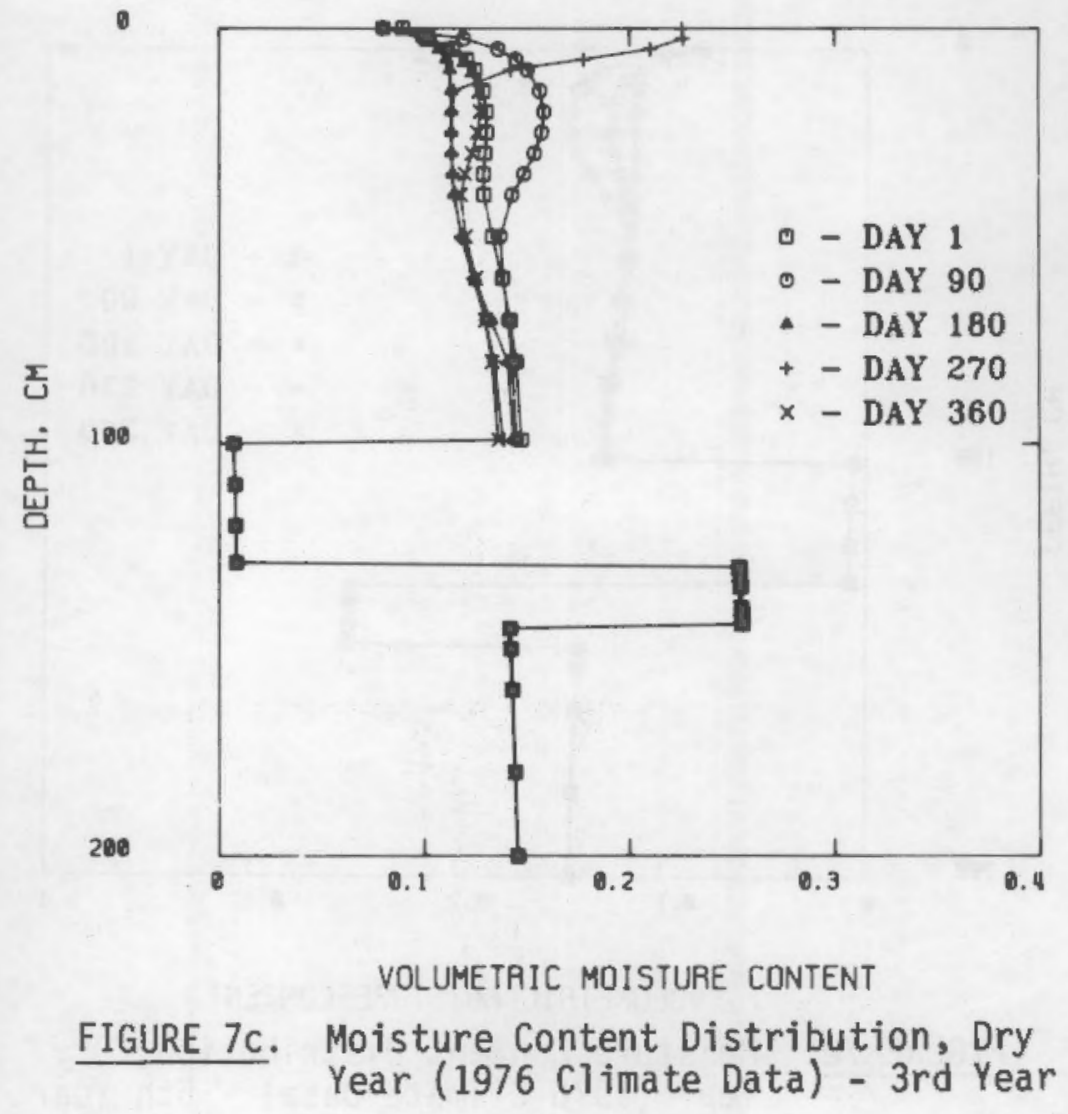




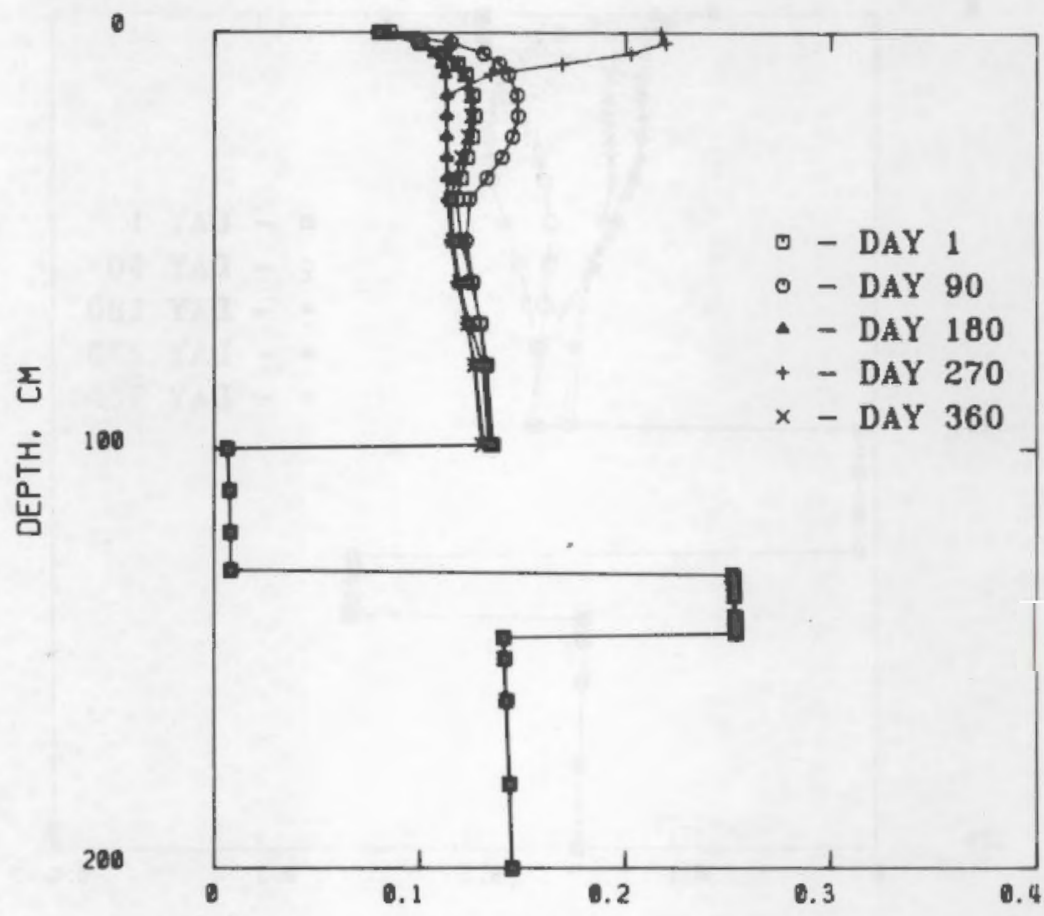

VOLUMETAIC MOISTURE CONTENT

FIGURE 7d. Moisture Content Distribution, Dry Year (1976 Climate Data) - 4th Year

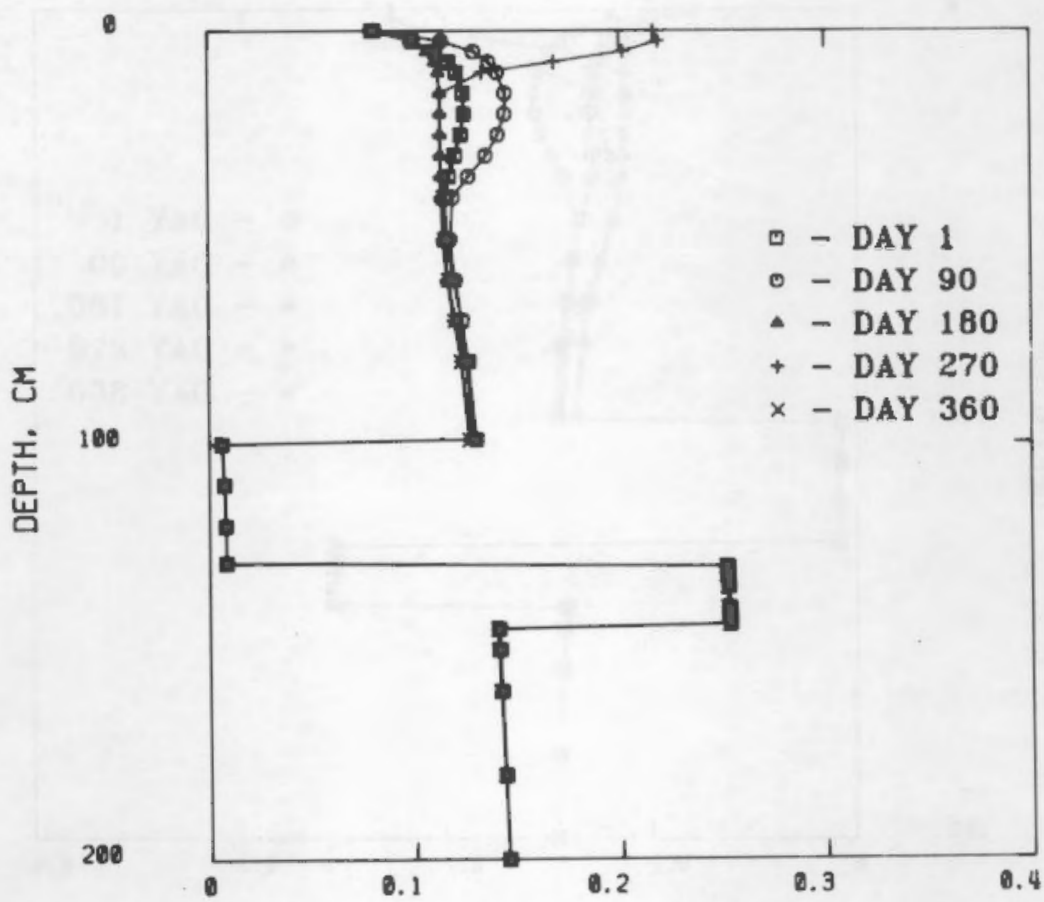

VOLUMETAIC MOISTURE CONTENT

FIGURE 7e. Moisture Content Distribution, Dry Year (1976 Climate Data) - 5th Year 


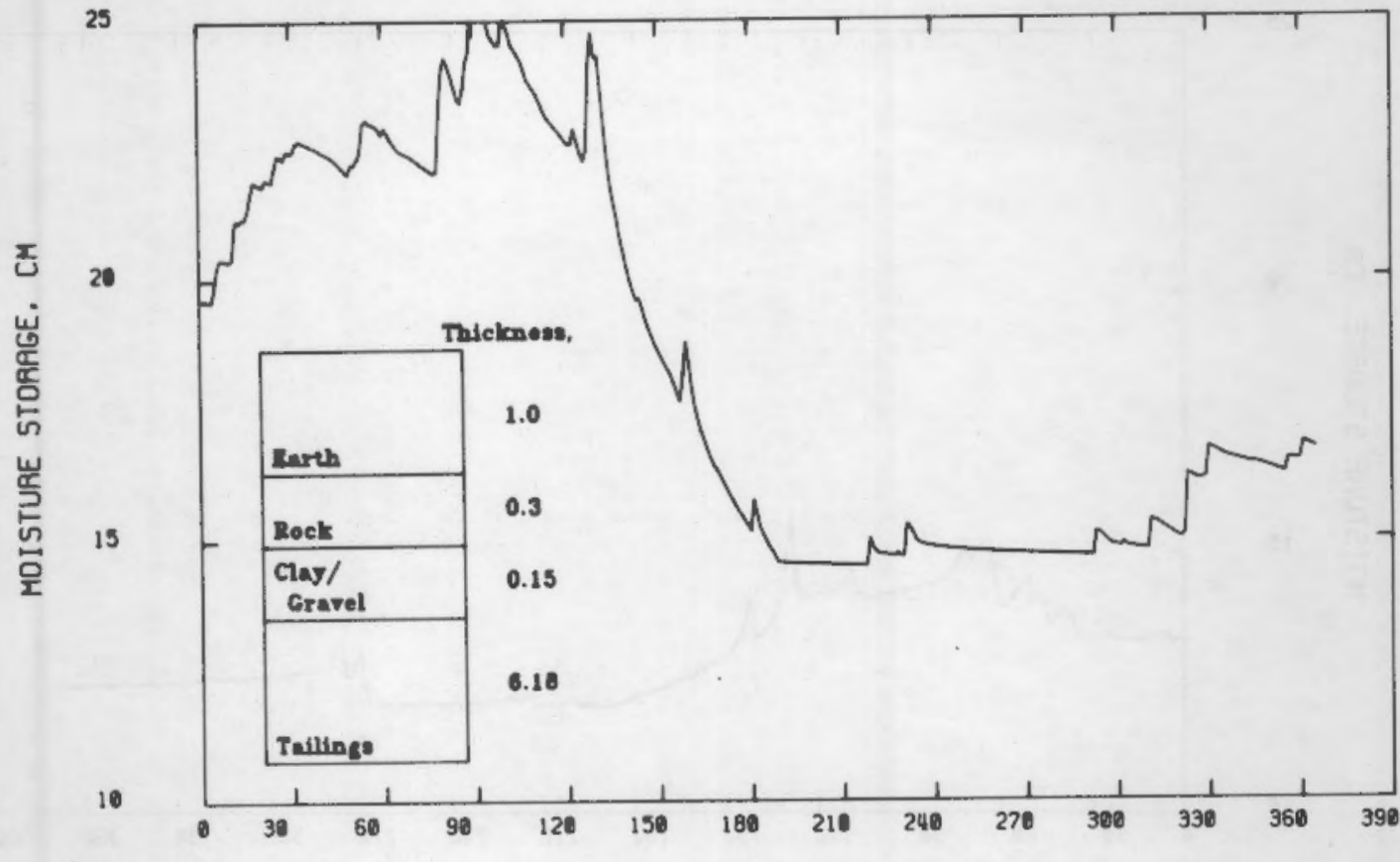

TIME. DAYS

FIGURE 8a. Moisture Storage for Top $100 \mathrm{~cm}$, Wet Year (1979 Climate Data) - 1st Year

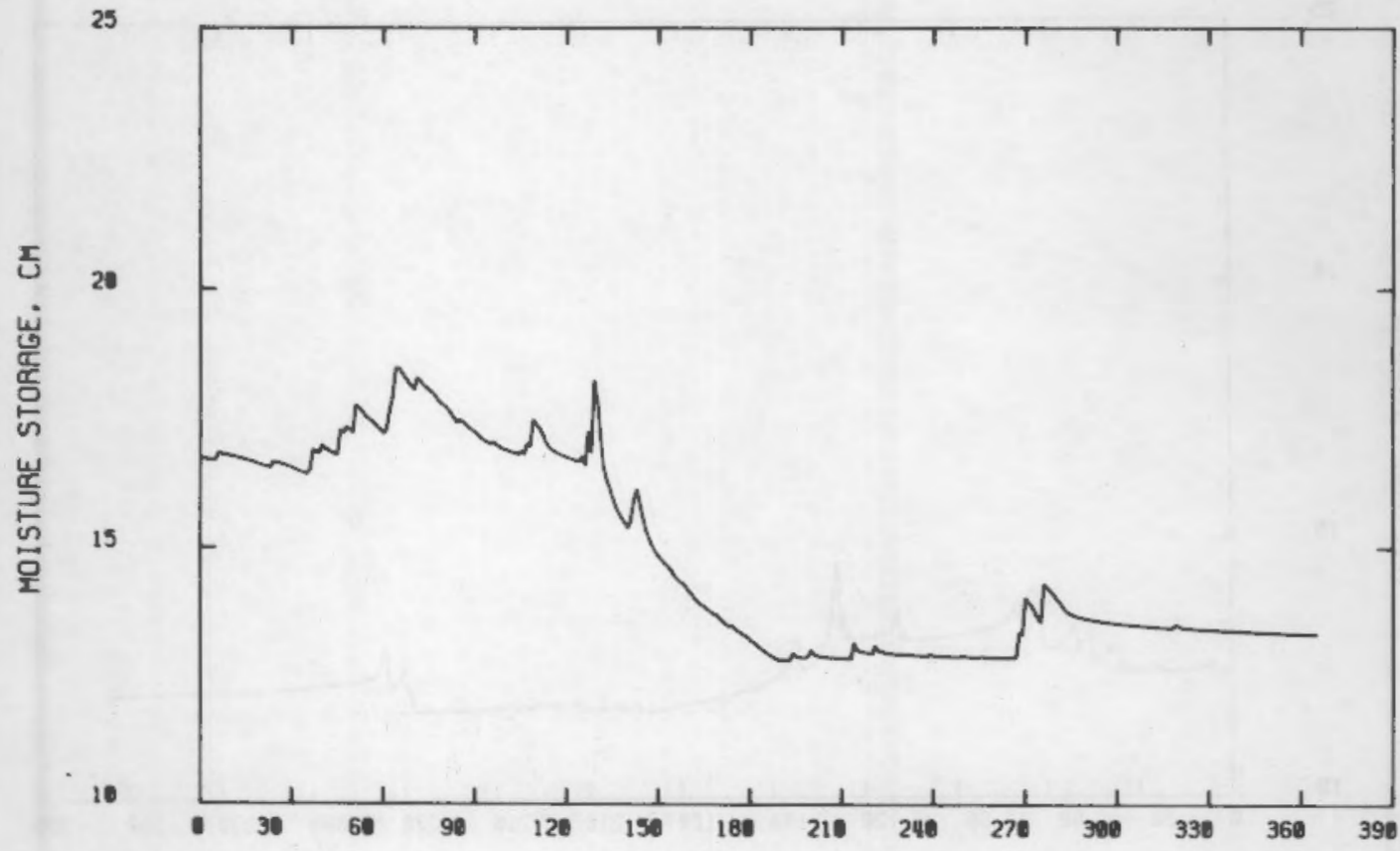

TIME. DAYS

FIGURE 8b. Moisture Storage for Top $100 \mathrm{~cm}$, Dry Year (1976 Climate Data) - 2nd Year 


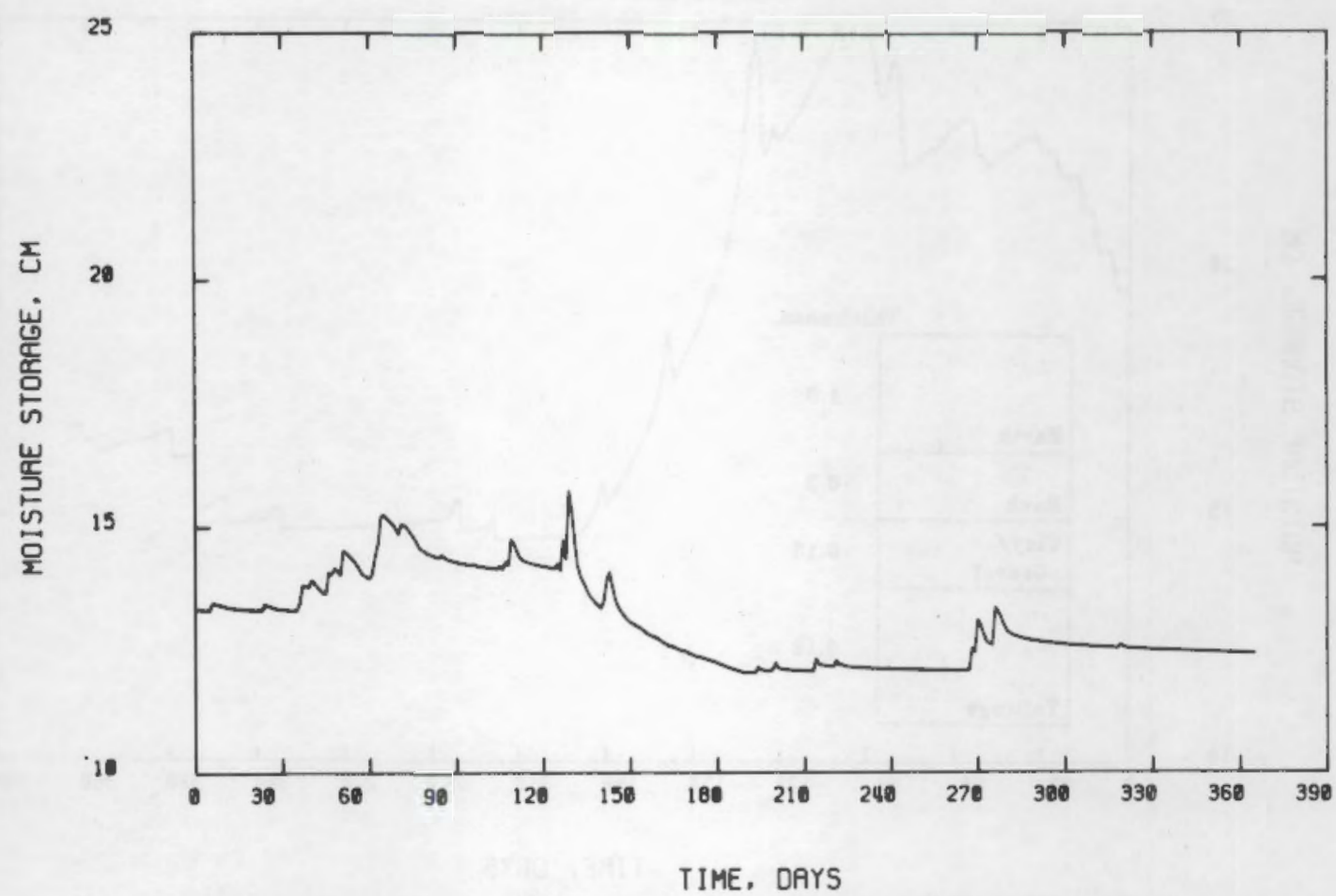

FIGURE 8c. Moisture Storage for Top $100 \mathrm{~cm}$, Dry Year (1976 Climate Data) - 3rd Year

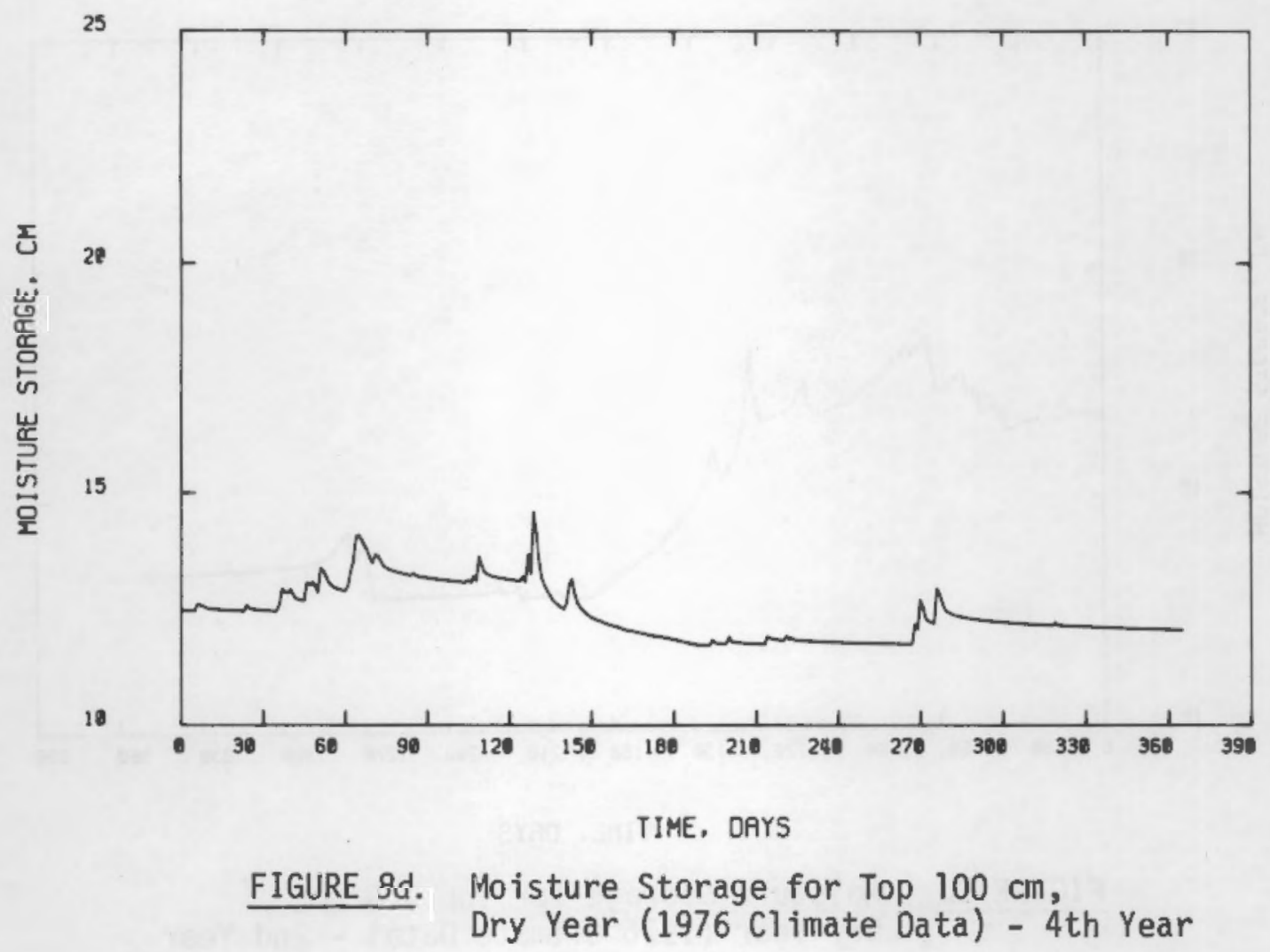




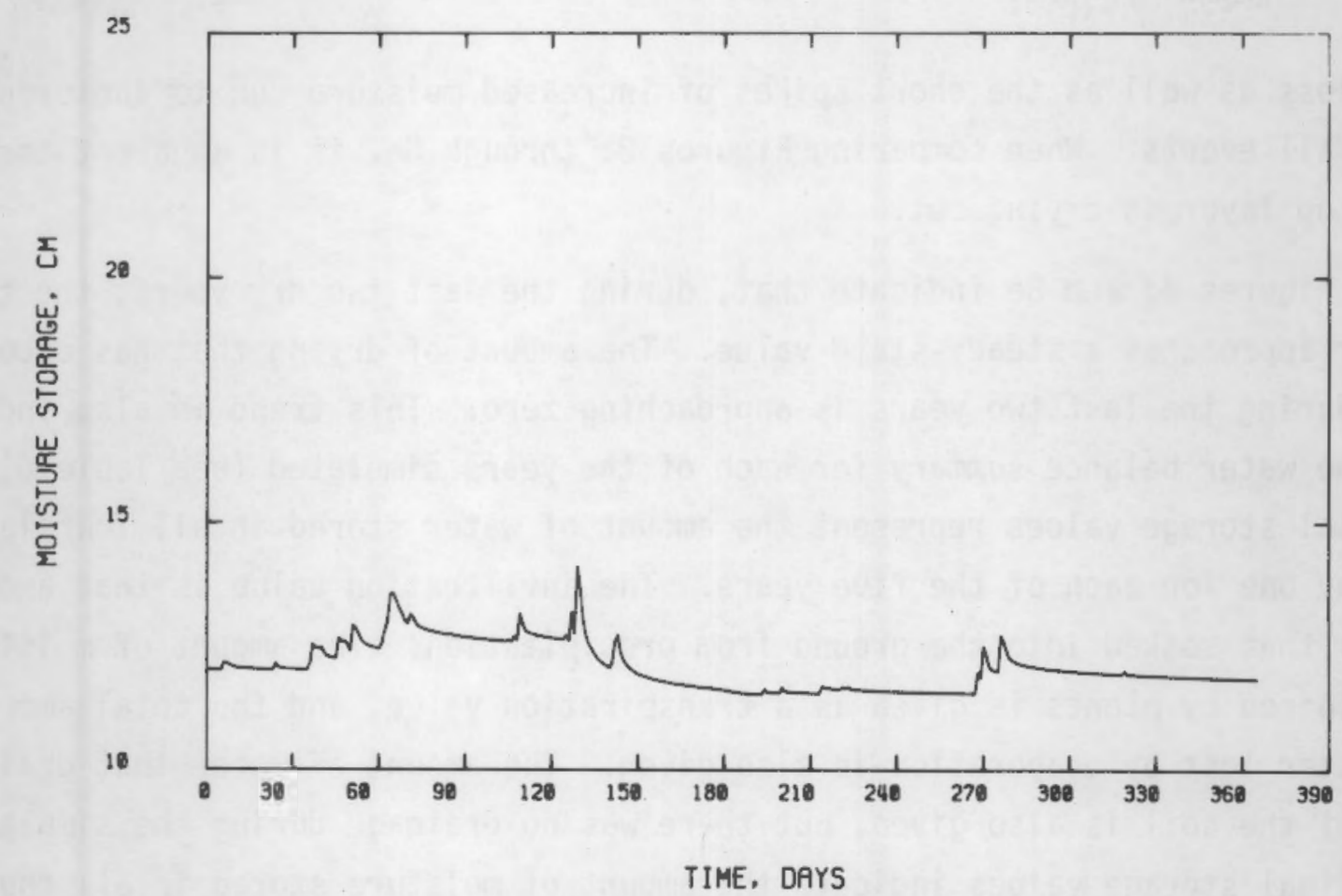

FIGURE 8e. Moisture Storage for Top $100 \mathrm{~cm}$, Dry Year (1976 Cl imate Data) - 5th Year

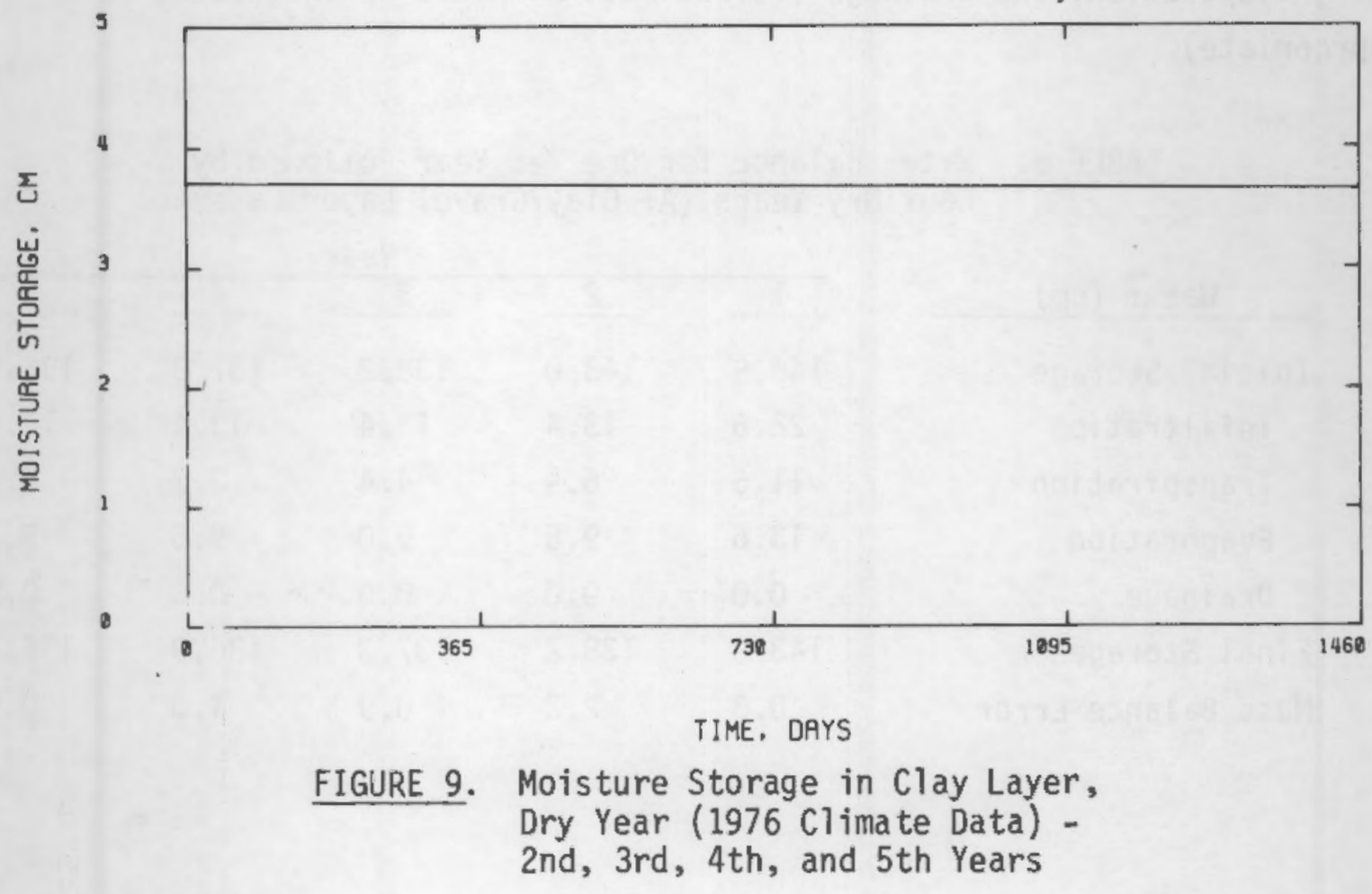


and loss as well as the short spikes of increased moisture due to individual rainfall events. When comparing Figures $8 \mathrm{a}$ through $8 \mathrm{e}$, it is apparent that the top layer is drying out.

Figures $8 \mathrm{~d}$ and $8 \mathrm{e}$ indicate that, during the last two dry years, the top cover approaches a steady-state value. The amount of drying that has occurred during the last two years is approaching zero. This trend is also indicated by the water balance summary for each of the years simulated (see Table 6). The initial storage values represent the amount of water stored in all four layers on day one for each of the five years. The infiltration value is that amount of water that soaked into the ground from precipitation. The amount of moisture transpired by plants is given as a transpiration value, and the total amount of water lost by evaporation is also given. The amount of water that drained out of the soil is also given, but there was no drainage during the simulation. The final storage values indicate the amount of moisture stored in all four layers on the last day of each year. The mass balance error is the difference that occurs when the change in water storage is computed as the difference in initial and final water storage or as the sum of the infiltration, transpiration, evaporation, and drainage (values must be added or subtracted as appropriate).

TABLE 6. Water Balance for One Wet Year Followed by Four Dry Years (A+ Clay/Gravel Layer Case)

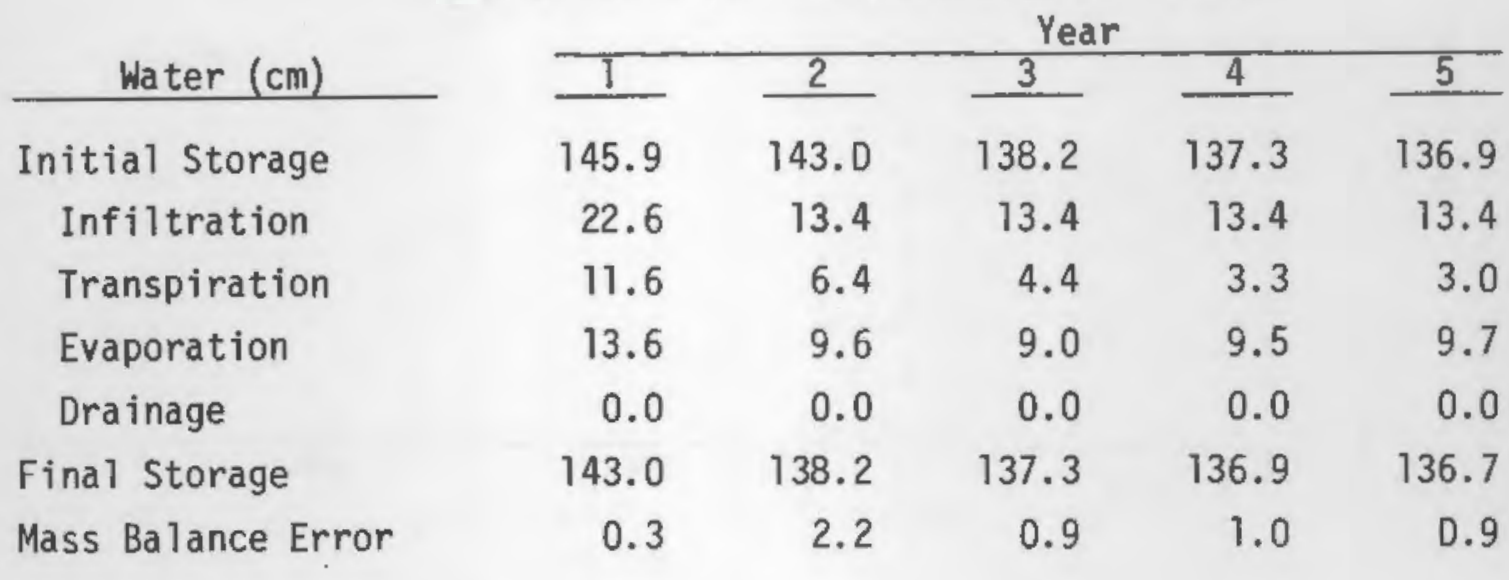


Figure 9 demonstrates that the clay/gravel layer is reasonably isolated from the effects of the varying climatic conditions. A nearly negligable amount of drying can be noted, and it is apparent that short-period rainfall events and seasonal moisture gain and loss do not cause an observable effect on the moisture storage in the clay/gravel layer. For this reason, a cover system like this is considered an engineered moisture-control system. The top cover layer provides a place for plants to grow and animals to burrow. The next layer (clean rock) forms a capillary barrier that serves to isolate the lower layers from the varying moisture content in the top layer. The capillary barrier helps to maintain a relatively high moisture content in the clay/gravel layer (refer to Figure $7 \mathrm{a}$ through $7 \mathrm{e}$ ). The high moisture content in the clay/gravel layer results in a low value for the diffusion coefficient in that layer and, hence, can effectively control the emission of radon gas from the tailings pile.

To illustrate the effect of moisture content on radon diffusion, the transient radon diffusion mode1, RNDI1D, has been run using the time varying moisture contents predicted by the partialy saturated flow analysis and the layer characteristics listed in Table 4. The diffusion coefficient for each layer was computed by Equation (3). The resulting surface fluxes are plotted in Figures 10a through 10e.

The radon diffusion simulations were started with a zero radon gas concentration throughout the tailings and covers. Hence, a period of time must pass before the surface flux becomes established. This is represented by the low surface fluxes during the first month of the simulation. As time progresses, however, the surface fluxes become larger and reach their highest value during the last year of the simulation. This is an expected result, since the gradual drying out of the cover system results in higher diffusion rates. The effect of rainfall events is also demonstrated by the downward spikes in the surface flux. These spikes coincide with the upward spikes on the moisture storage figures (Figures $8 \mathrm{a}$ through $8 \mathrm{~b}$ ) that are due to precipitation.

Another simulation of a nearly identical cover system has been performed. The only difference between this and the previous simulation is that a different clay/gravel mix (A- clay/gravel mix) was used for the clay/gravel layer. The 


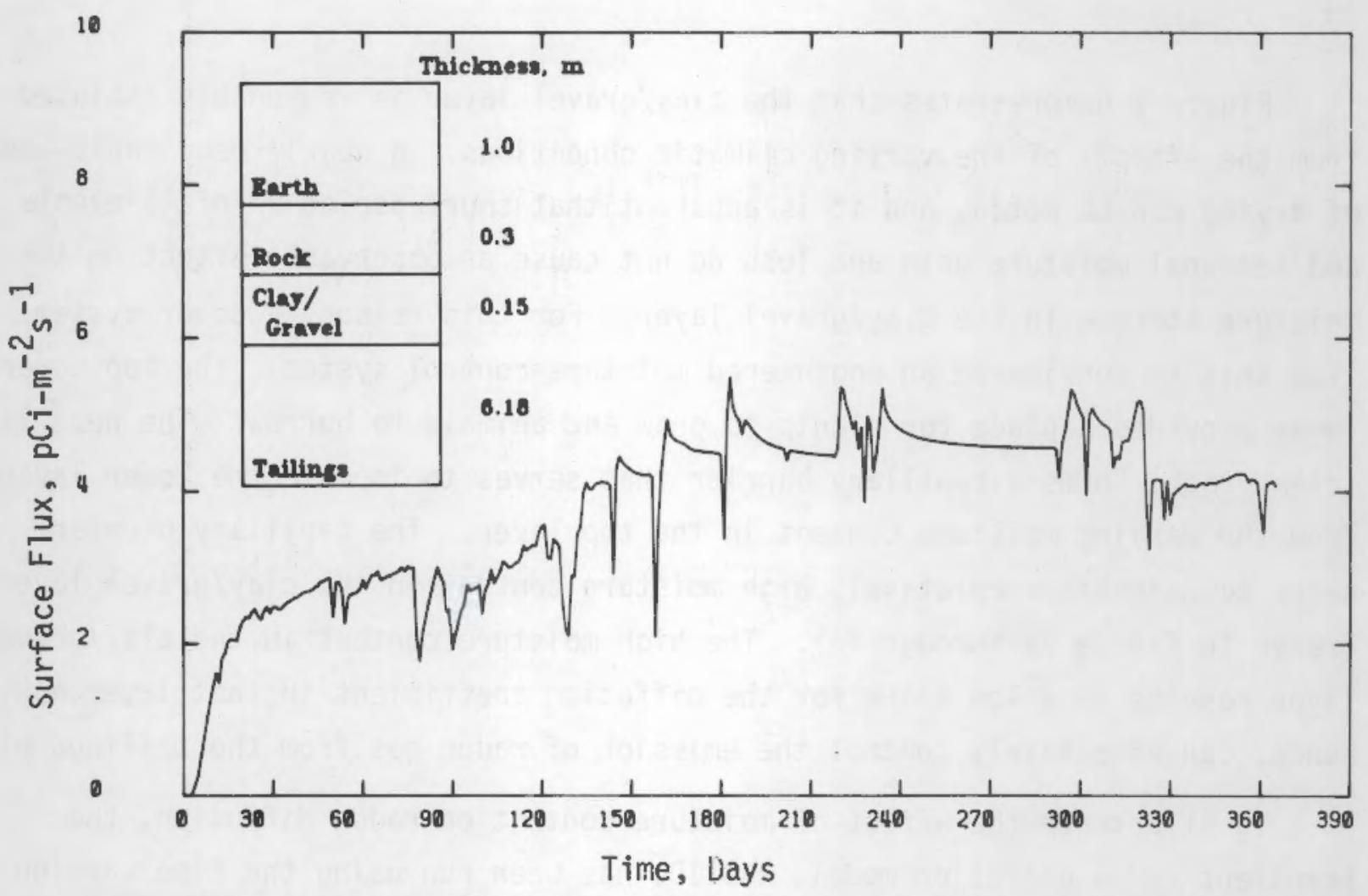

FIGURE 10a. Radon Gas Surface Flux, Wet Year (1979 Climate Data) - 1st Year

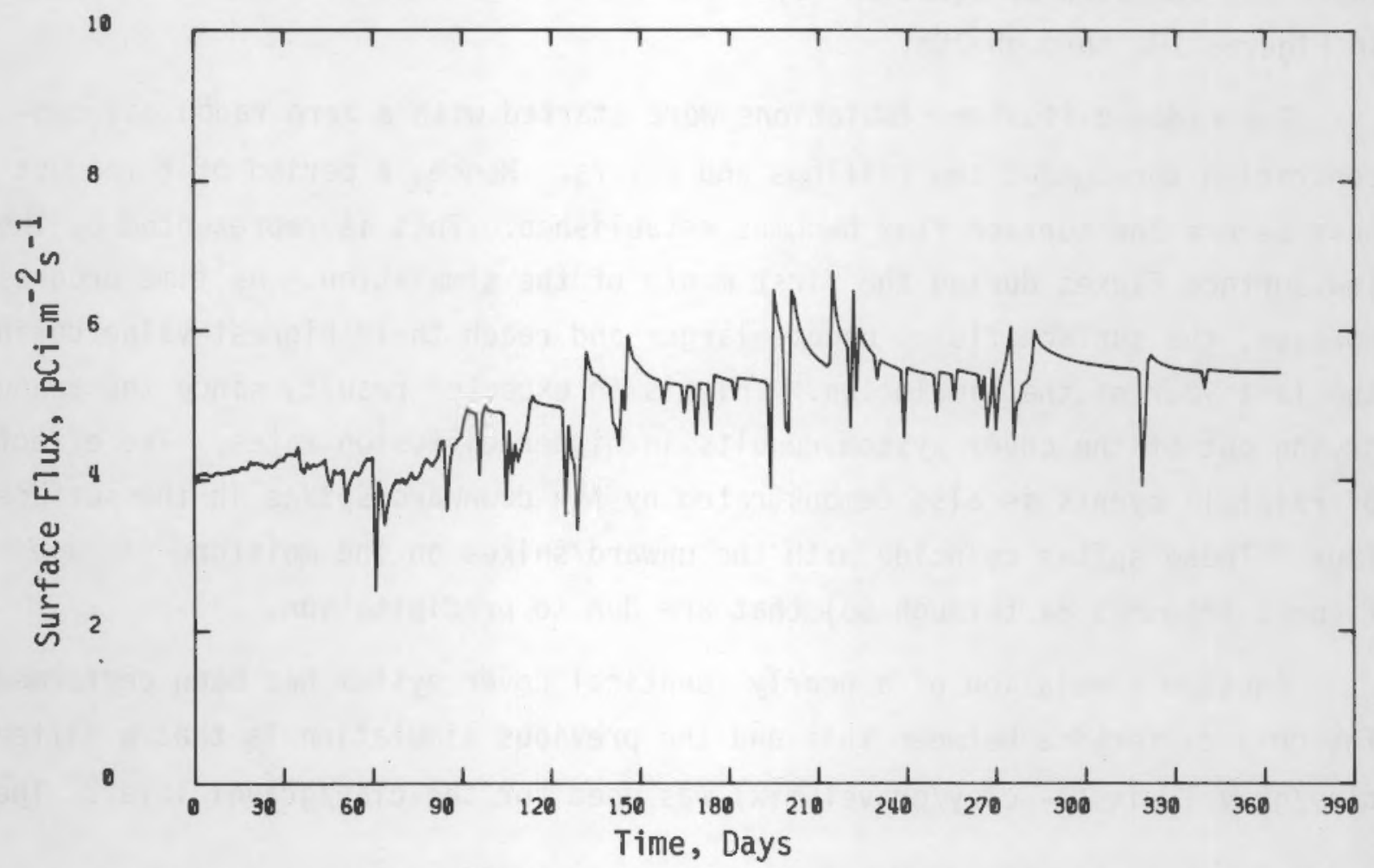

FIGURE 10b. Radon Gas Surface Flux, Dry Year (1976 Climate Data) - 2nd Year 


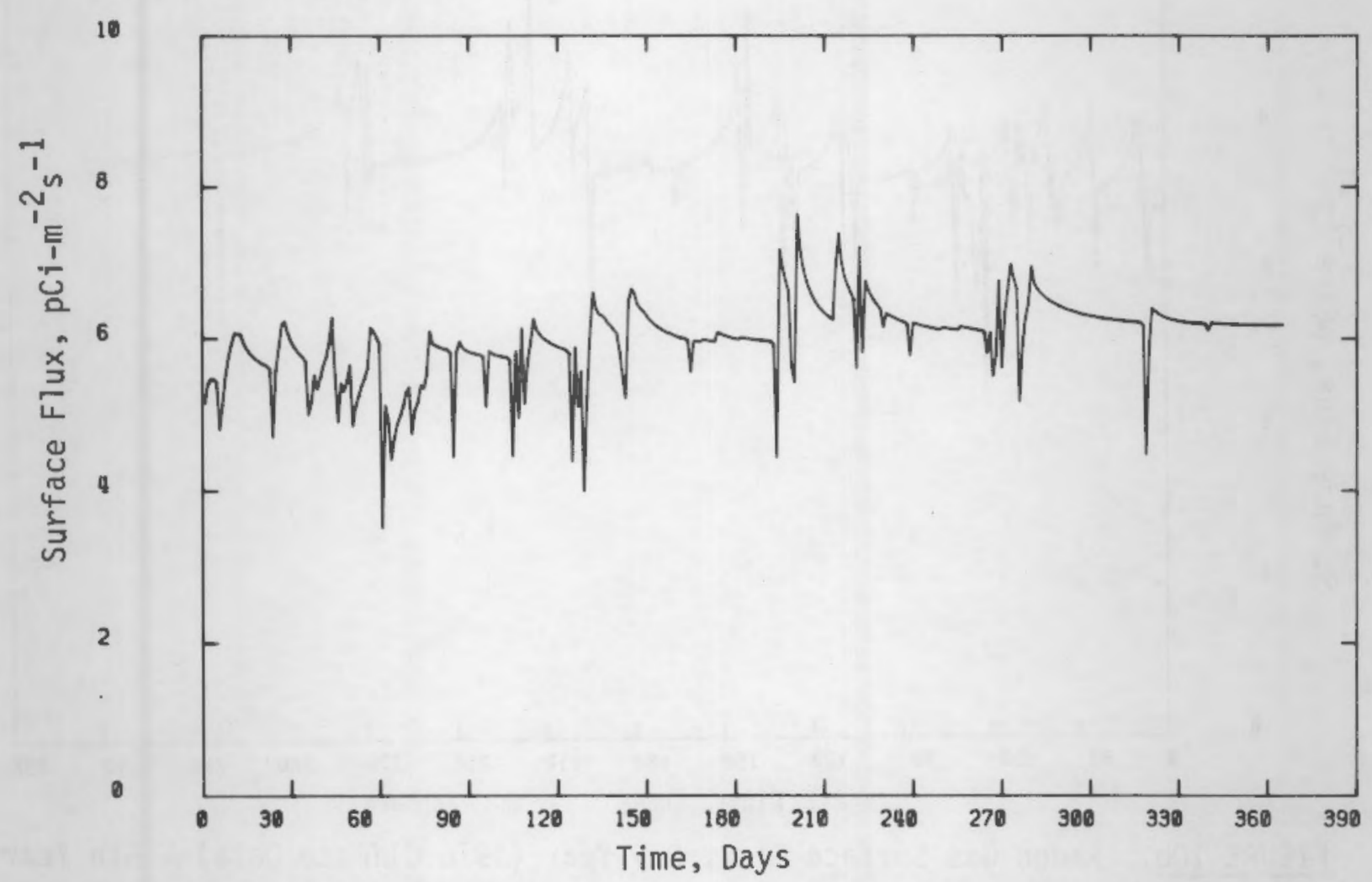

FIGURE 10c. Radon Gas Surface Flux, Dry Year (1976 Climate Data) - 3rd Year

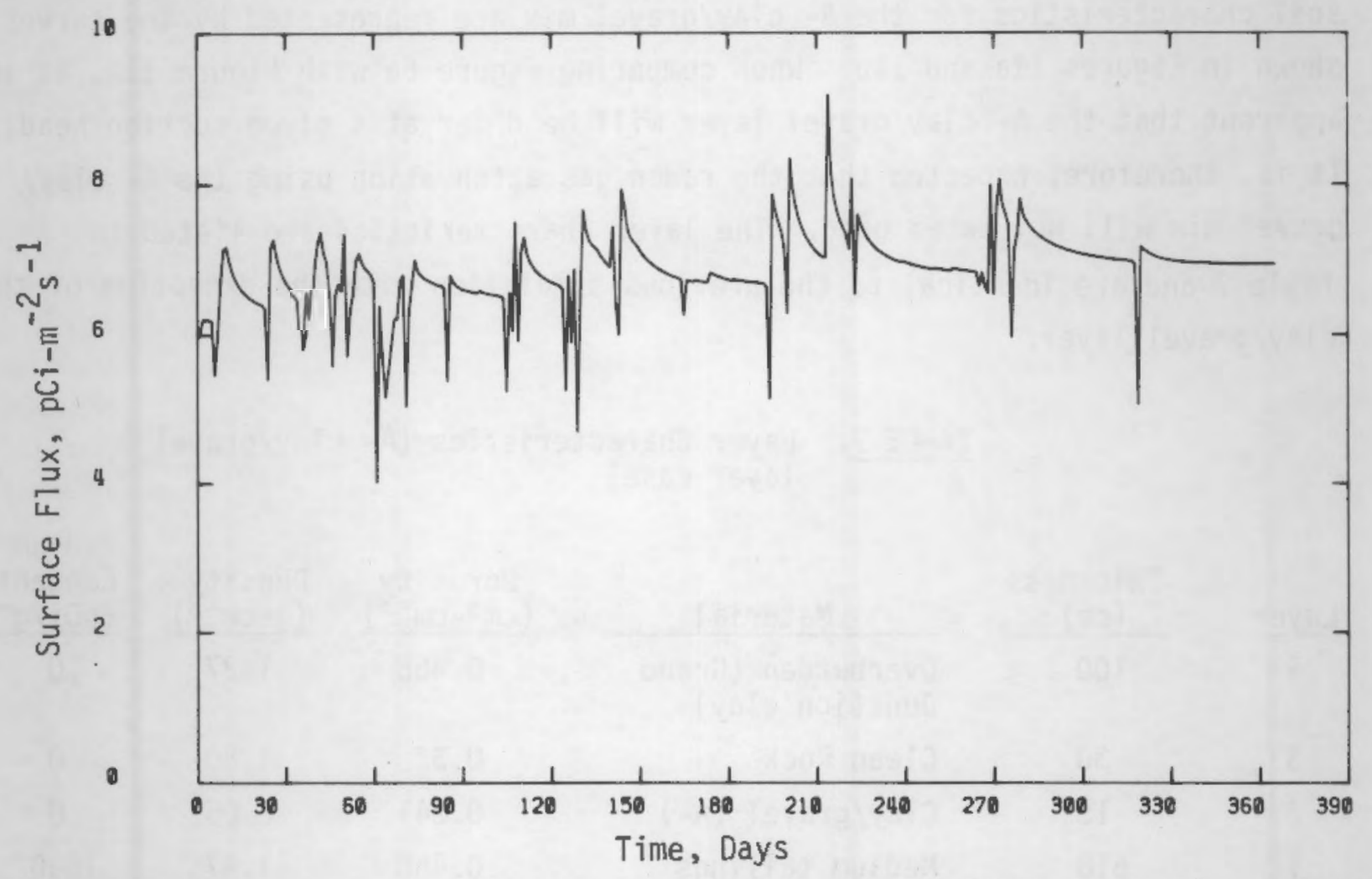

FIGURE 10d. Radon Gas Surface Flux, Dry Year (1976 Climate Date) - 4th Year 


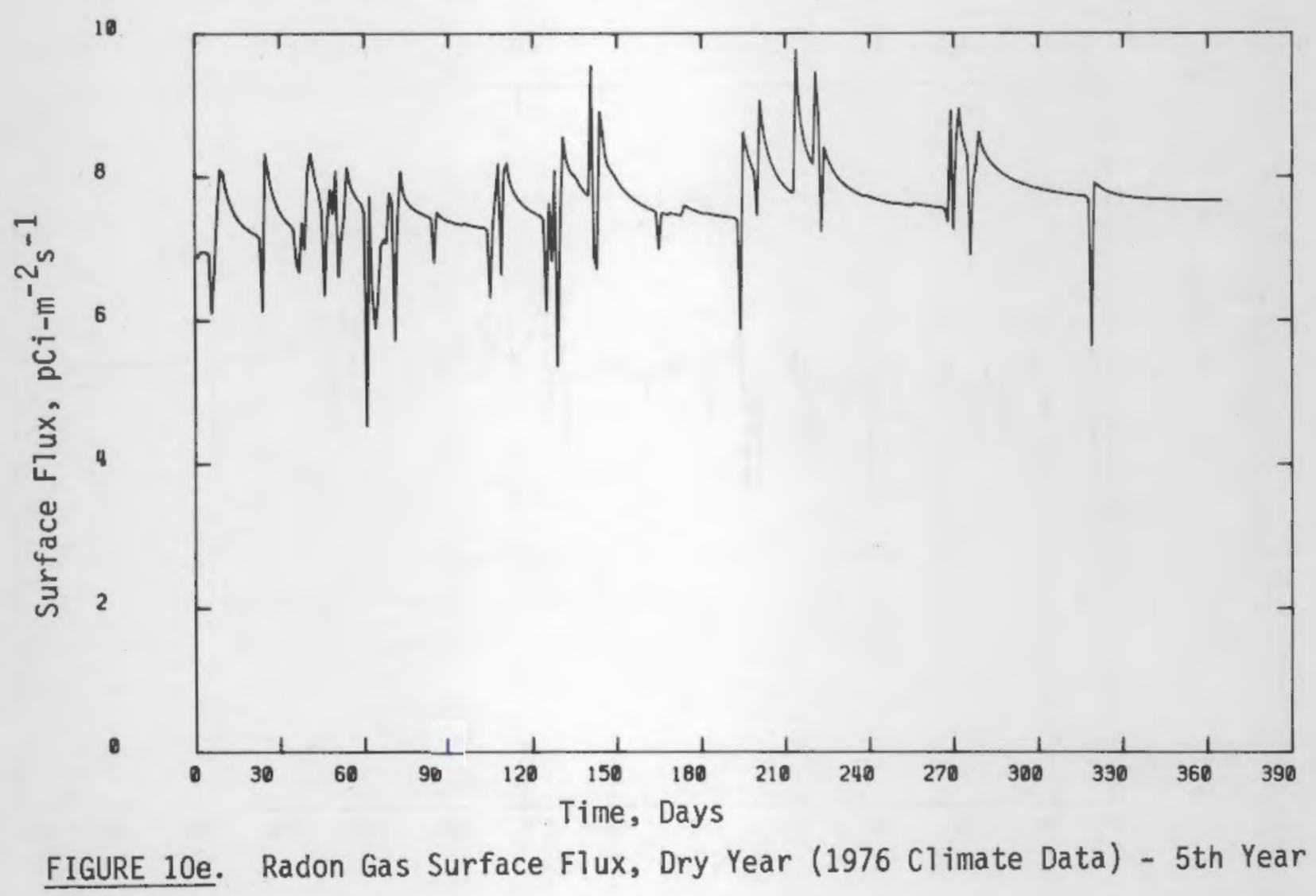

soil characteristics for the A- clay/gravel mix are represented by the curves shown in Figures 11a and 11b. When comparing Figure 6a with Figure 11a, it is apparent that the A- clay/gravel layer will be drier at a given suction head. It is, therefore, expected that the radon gas attenuation using the A- clay/ gravel mix will not be as good. The layer characteristics are listed in Table 7 and are identical to the previous simulation with the exception of the clay/gravel layer.

TABLE 7. Layer Characteristics (A- clay/gravel layer case)

\begin{tabular}{|c|c|c|c|c|c|}
\hline Layer & $\begin{array}{l}\text { Thickness } \\
\text { (cm) }\end{array}$ & Material & $\begin{array}{l}\text { Porosity } \\
\left(\mathrm{cm}^{3}-\mathrm{cm}^{-3}\right)\end{array}$ & $\begin{array}{l}\text { Density } \\
\left(\mathrm{g}-\mathrm{cm}^{-3}\right)\end{array}$ & $\begin{array}{l}\text { Radium } \\
\text { Content } \\
\left.\text { (pCi } / \mathrm{g}^{-1}\right)\end{array}$ \\
\hline 4 & 100 & $\begin{array}{l}\text { Overburden (Grand } \\
\text { Junction clay) }\end{array}$ & 0.468 & 1.37 & 0 \\
\hline 3 & 30 & Clean Rock & 0.32 & 1.80 & 0 \\
\hline 2 & 15 & $\mathrm{Clay} /$ gravel (A-) & 0.241 & 2.05 & 0 \\
\hline 1 & 618 & Medium tailings & 0.458 & 1.47 & 1600 \\
\hline
\end{tabular}




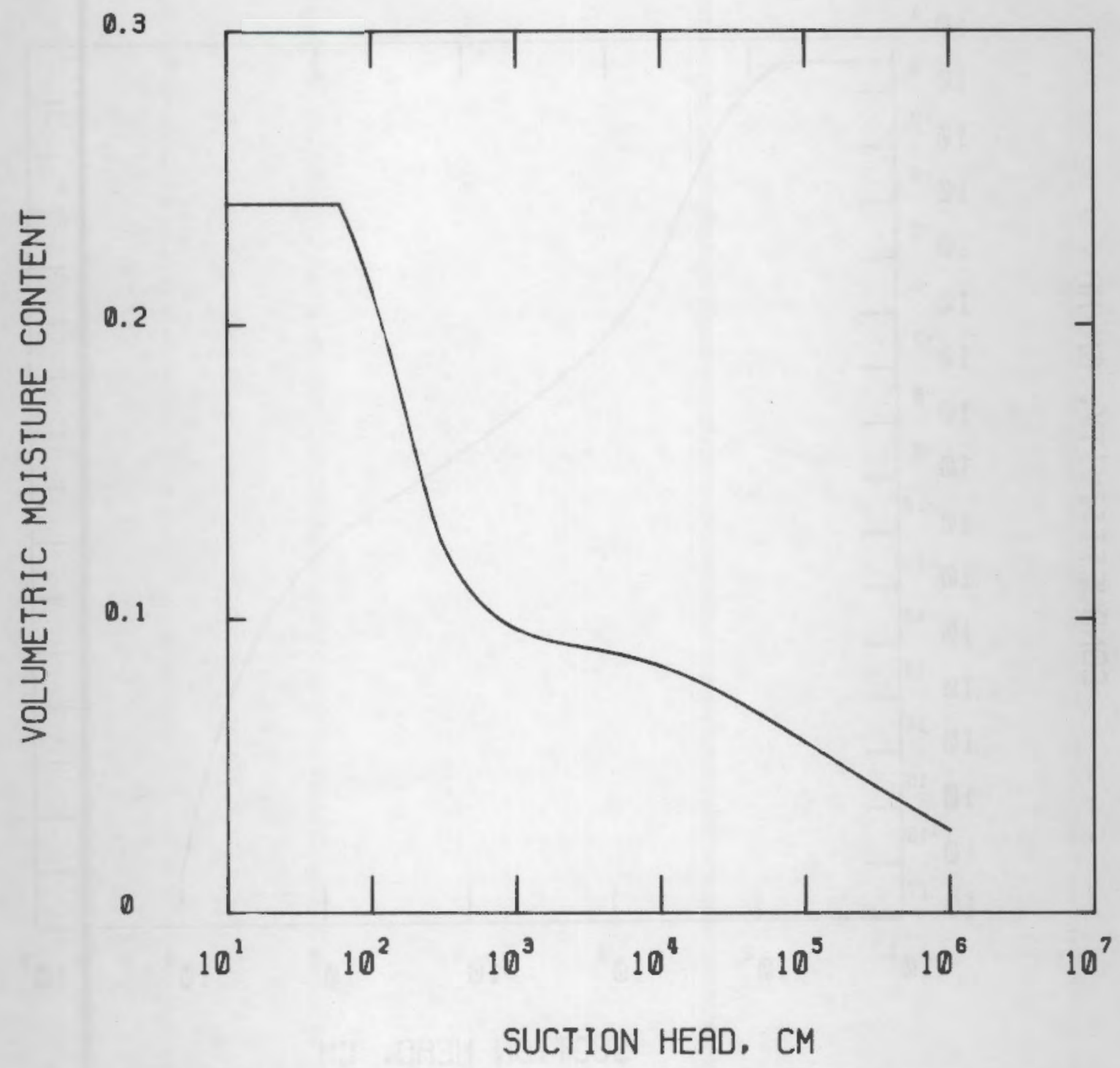

FIGURE 11a. A- Clay/Gravel Mix Soil Water Characteristic, Moisture Content Versus Suction Head

The moisture content profile at the end of the first year from the previous simulation was used as an initial condition. Only one dry year was modeled for this simulation. Figure 12 is a plot of the resulting moisture content profiles for selected days during the simulation. Comparison of these profiles with Figure 7b indicates that the only difference is that the clay/gravel layer is significantly drier: it is only $40 \%$ as wet as the previous clay/gravel layer. The water balance for this simulation is 1isted in Table 8. A 


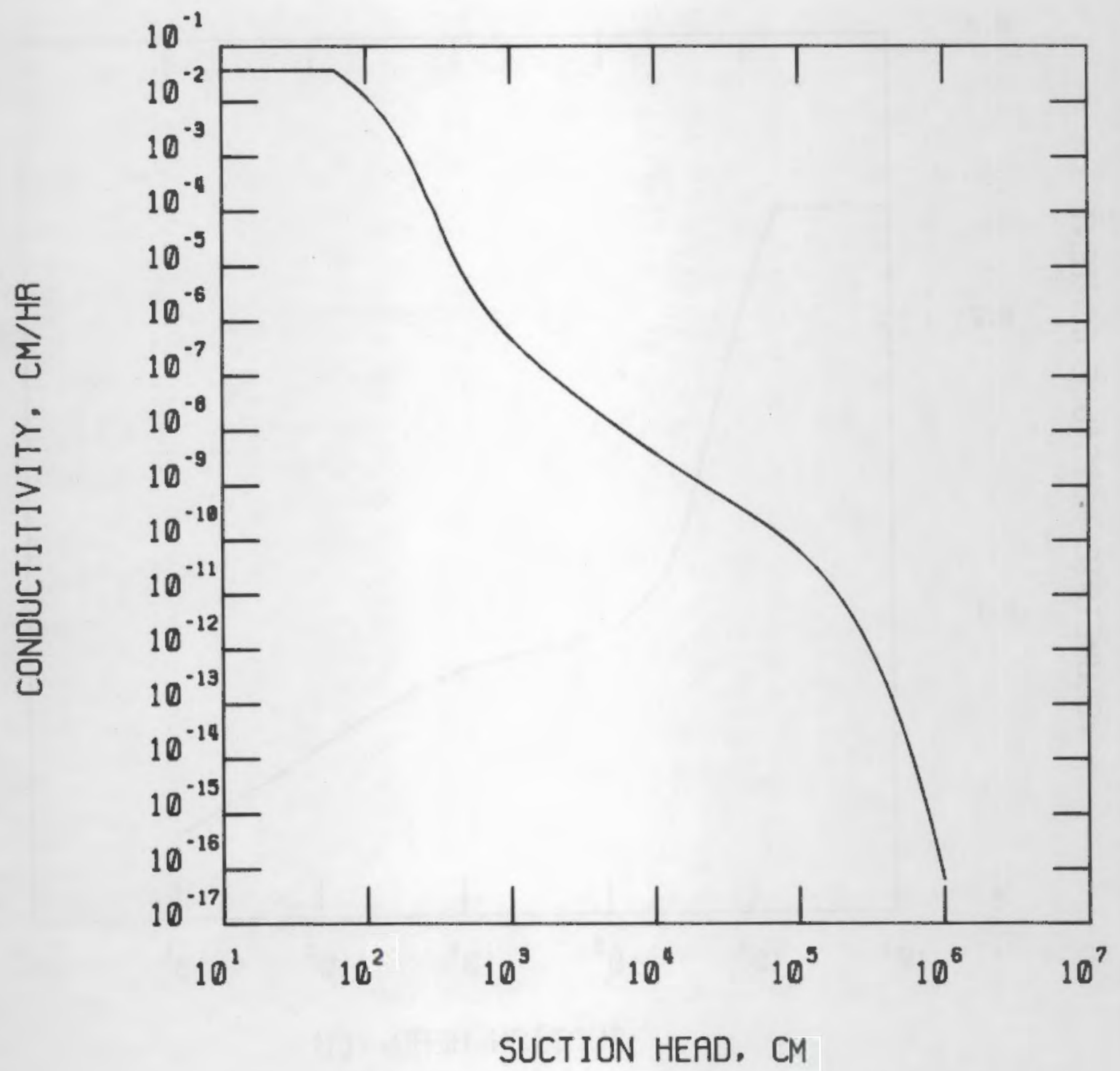

FIGURE 11b. A- Clay/Gravel Mix Soil Water Characteristic, Conductivity Versus Suction Head

comparison of Table 8 with the first two years listed in Table 6 demonstrates that the A- clay/gravel layer is unable to maintain as high a moisture storage as the A+ clay/gravel layer. The final storage value for the second year is $2.3 \mathrm{~cm}$ of water less than the A+ clay/gravel layer case.

Figure 13 is the resulting moisture storage in the top layer. Not surprisingly, the moisture storage in the top layer is identical to the moisture storage in the previous simulation (Figure 13 and Figure $8 \mathrm{~b}$ ). 


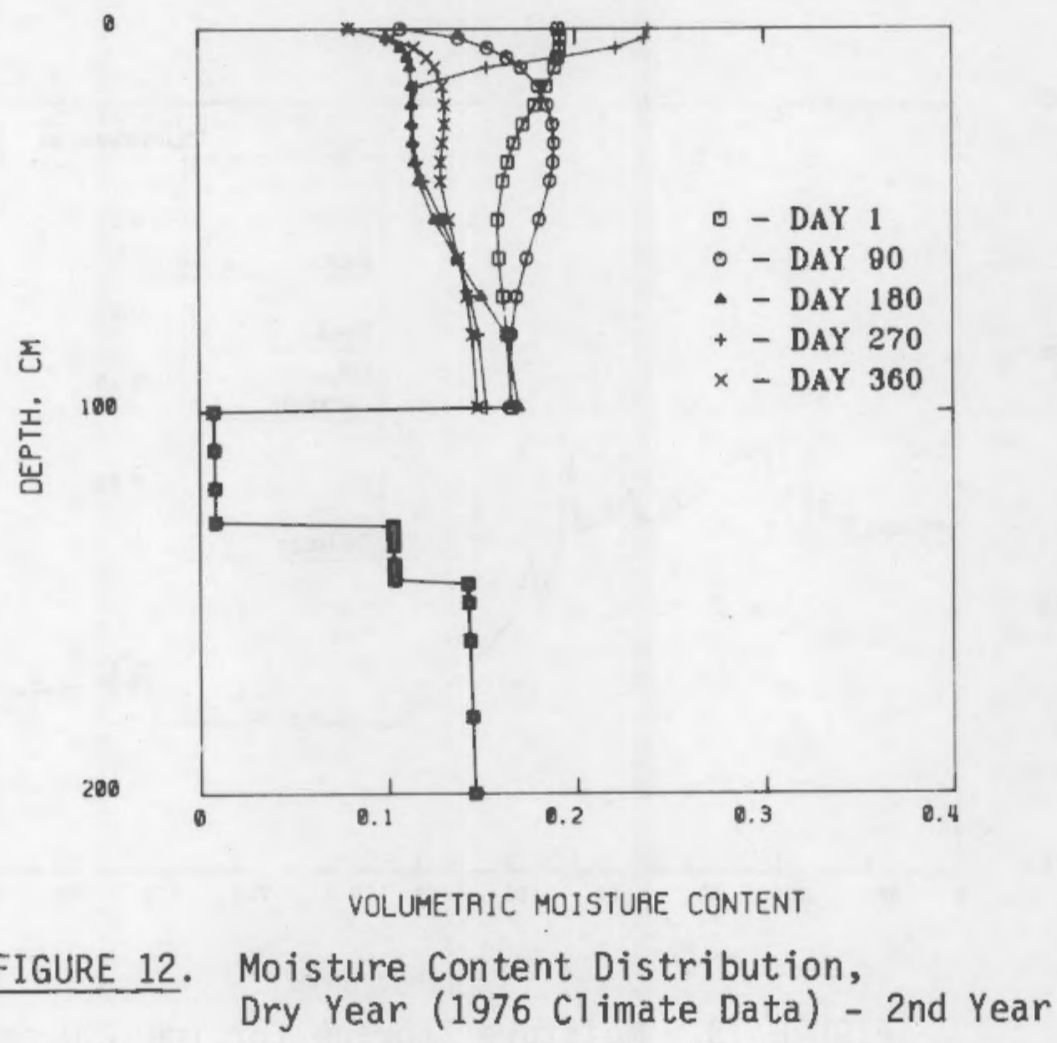

TABLE 8. Water Balance for One Wet Year Followed by One Dry Year (A- clay/gravel layer case)

\begin{tabular}{|c|c|c|}
\hline \multirow[b]{2}{*}{ Water $(\mathrm{cm})$} & \multicolumn{2}{|c|}{ Year } \\
\hline & 7 & 2 \\
\hline Initial Storage & 145.9 & 140.0 \\
\hline Infiltration & 22.6 & 13.4 \\
\hline Transpiration & 11.6 & 6.4 \\
\hline Evaporation & 13.6 & 9.6 \\
\hline Drainage & 0.0 & 0.0 \\
\hline Final Storage & 143.0 & 135.9 \\
\hline Mass Balance Error & 0.3 & 1.5 \\
\hline
\end{tabular}

The surface flux (Figure 14) shows a dramatic increase over the previous results (Figure 10b). The surface flux with the $60 \%$ drier clay/gravel layer is roughly 35 times larger. This finding demonstrates the importance of maintaining a relatively high moisture content in the clay/gravel layer. A significant improvement in the control of radon emissions can be obtained if a 

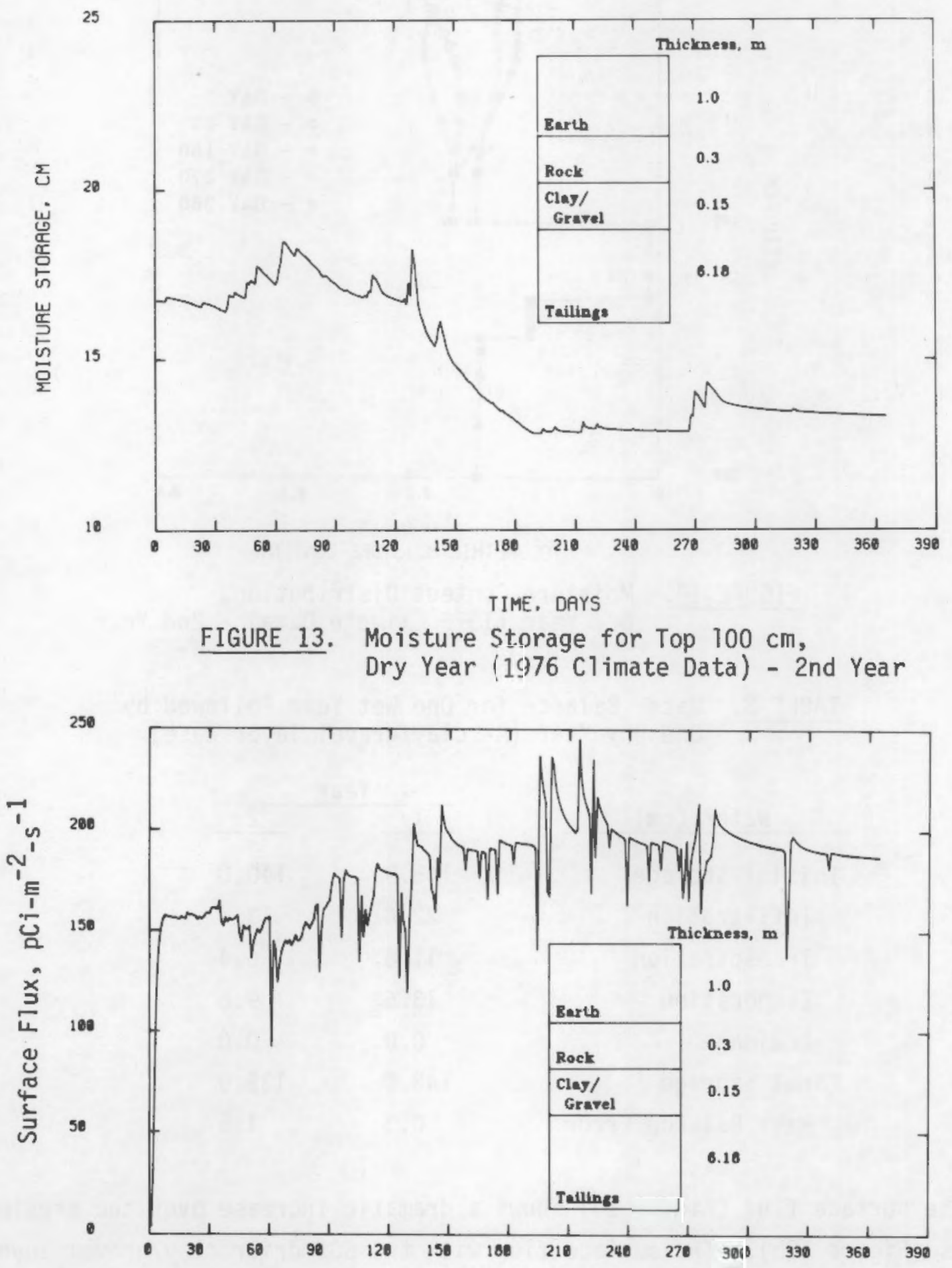

TIME, DAYS

FIGURE 14. Radon Gas Surface Flux, Dry Year (1976 Climate Data) - 2nd Year 
properly engineered cover system is used. Consideration should be given to maintaining relatively high moisture content in the cover system.

TWO-DIMENSIONAL

Two-dimensional (and three-dimensional) analysis of radon gas diffusion becomes important whenever a spatially nonuniform geometry or boundary condition exists. A nonuniform condition will exist whenever there are spatial variations in thickness, porosity, moisture content, or radium content. Nonuniform boundary conditions arise near the edge of the tailings pile, near the apparatus used to measure flux and concentrations, and whenever the specified flux or concentration varies spatially. For these reasons, the capability to model multidimensional effects is very important.

The multidimensional radioactive diffusion code, RADMD, is capable of simulating the multidimensional effects of spatial variations for both steady state and transient problems. As a first step in verifying the code, a simple one-dimensional problem has been simulated and compared with the analytic solution. The problem solved deals with bare tailings having the layer characteristics shown in Table 9 (for Layer 1 ). The diffusion coefficient of the layer was selected to be $10^{-4} \mathrm{~cm}^{2}-\mathrm{s}^{-1}$. A concentration of zero is imposed at the surface and the flux into the bottom of the tailings is assumed to be zero. The finite difference grid used to simulate this problem consists of a column of 48 cells that are $12.5 \mathrm{~cm}$ thick. The nodes are cell centered with an additional node placed at the surface of the tailings.

TABLE 9. Layer Characteristics for Discontinuous Cover Case

\begin{tabular}{|c|c|c|c|c|c|c|}
\hline Layer & $\begin{array}{l}\text { Thickness } \\
\text { (cm) }\end{array}$ & Material & $\begin{array}{c}\text { Total } \\
\text { Porosity } \\
\left(\mathrm{cm}^{3}-\mathrm{cm}^{-3}\right)\end{array}$ & $\begin{array}{c}\text { Bulk } \\
\text { Density } \\
\left(\mathrm{g}-\mathrm{cm}^{-3}\right) \\
\end{array}$ & $\begin{array}{c}\text { Moisture } \\
\text { Content } \\
\left(\mathrm{cm}^{3}-\mathrm{cm}^{-3}\right) \\
\end{array}$ & $\begin{array}{c}\text { Radium } \\
\text { Content } \\
\left.\text { (pCi-g } \mathrm{g}^{-1}\right)\end{array}$ \\
\hline 2 & 100 & $\begin{array}{l}\text { Overburden } \\
\text { (clay soil) }\end{array}$ & 0.48 & 1.404 & 0.433 & 0 \\
\hline 1 & 600 & Tailings & 0.55 & 1.230 & 0.190 & 1600 \\
\hline
\end{tabular}


The resulting concentration profile obtained with RADMD is shown in Figure 15, along with the analytic solution obtained by solving Equation (12). The results are in excellent agreement with the predicted concentrations; the results match the analytic solution with less than $3 \%$ error. The predicted bare tailings flux is $308.19 \mathrm{pCi}-\mathrm{cm}^{-2}-\mathrm{hr}^{-1}$, which matches the analytic solution obtained from Equation (11) with less than $0.2 \%$ error.

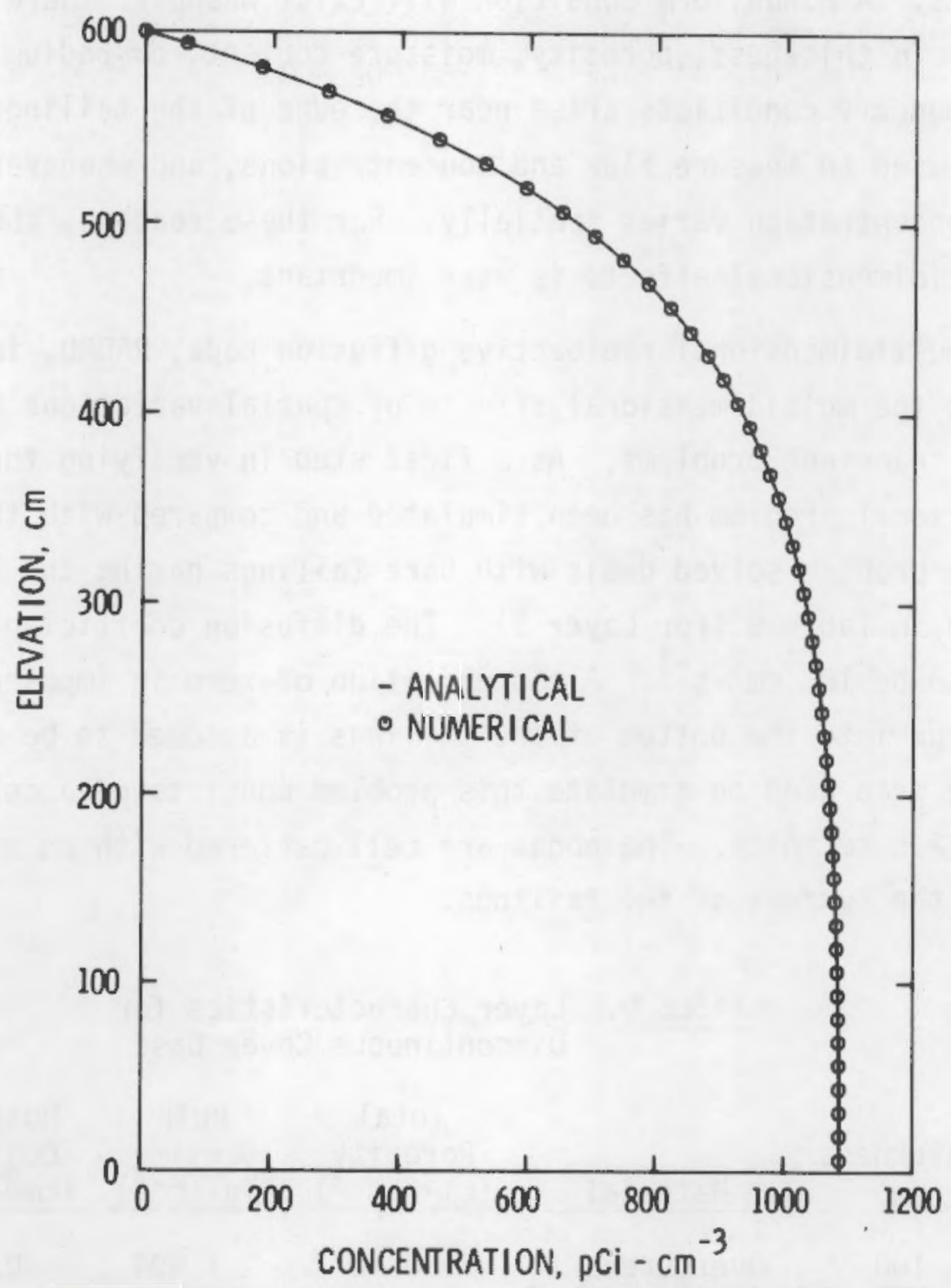

FIGURE 15. Analytical Versus Numerical Solution for $600-\mathrm{cm}$ Thick Bare Tailings 
To demonstrate the two-dimensional capability of the model, a tailings pile with a discontinuous cover has been simulated. The grid used for this case is shown in Figure 16. The variable grid size capability has been used to minimize the number of finite difference cells required and, at the same time, maintain sufficient resolution near the discontinuity. Based on the previous simulation, a $12.5-\mathrm{cm}$ cell width has been used at the tailings and cover interface and along the surface of the cover and tailings. Since reasonable accuracy was obtained using this cell width for the one-dimensional case, it was assumed that reasonable accuracy could be obtained for the discontinuous cover simulation. All of the finite difference nodes are cell centered and have additional nodes on the surface midway between cell boundaries. The concentration at all surface nodes was specified as zero, as was the flux into the bottom of the tailings layer. The characteristics of each layer are listed in Table 9.

The surface fluxes predicted by RADMD are shown in Figure 17. As expected, the surface flux values over the covered region are much smaller than over the uncovered tailings. The flux over the cover is on the order of $1.1 \mathrm{pCi}-\mathrm{cm}^{-2}-\mathrm{hr}^{-1}$,

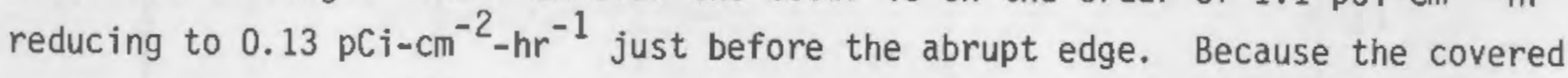
region reduces the diffusion of radon gas, the concentration under the cover builds up, resulting in an increased vertical surface flux from the bare tailings near the edge of the cover. The value of the surface flux from the bare tailings far from the cover is $299.3 \mathrm{pCi}-\mathrm{cm}^{-2}-\mathrm{hr}^{-1}$. As expected, the flux from the edge of the cover is near zero near the top of the cover and increases as the tailings layer is approached.

The two-dimensional effect of the discontinuous cover is illustrated in Figure 18. Concentration profiles $450 \mathrm{~cm}$ to either side of the cover edge and to a depth of $550 \mathrm{~cm}$ from the cover top are shown. This plot shows the high radon concentration that occurs under the cover. At distances greater than $450 \mathrm{~cm}$, the concentration profiles are essentially flat. This indicates that the two-dimensional influence of the abrupt edge is no longer being felt. It should be possible, therefore, to check the numerical results with the analytic calculations for one-dimensional radon diffusion. Figure 19 is the concentraion profile through the center of the far left column of cells shown in 


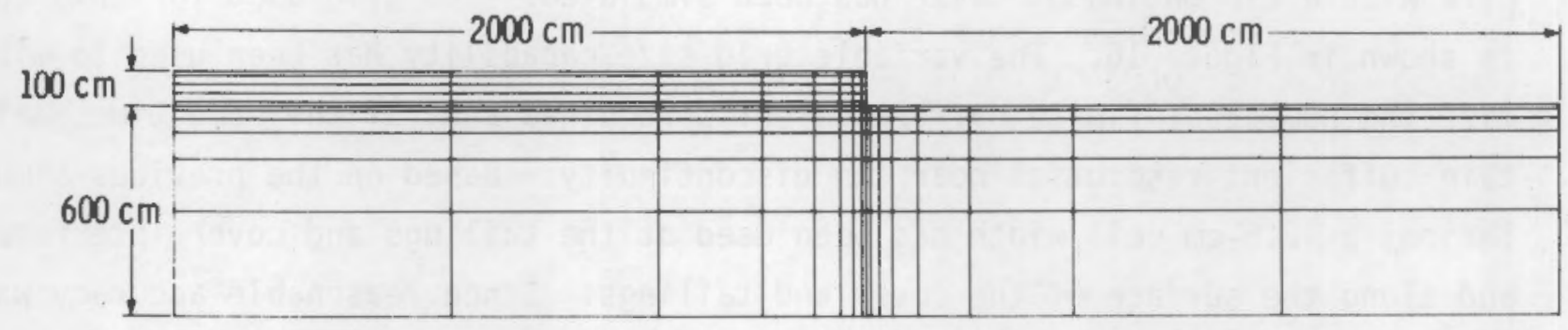

FIGURE 16. Two-Dimensional Grid for Discontinuous Cover Simulation

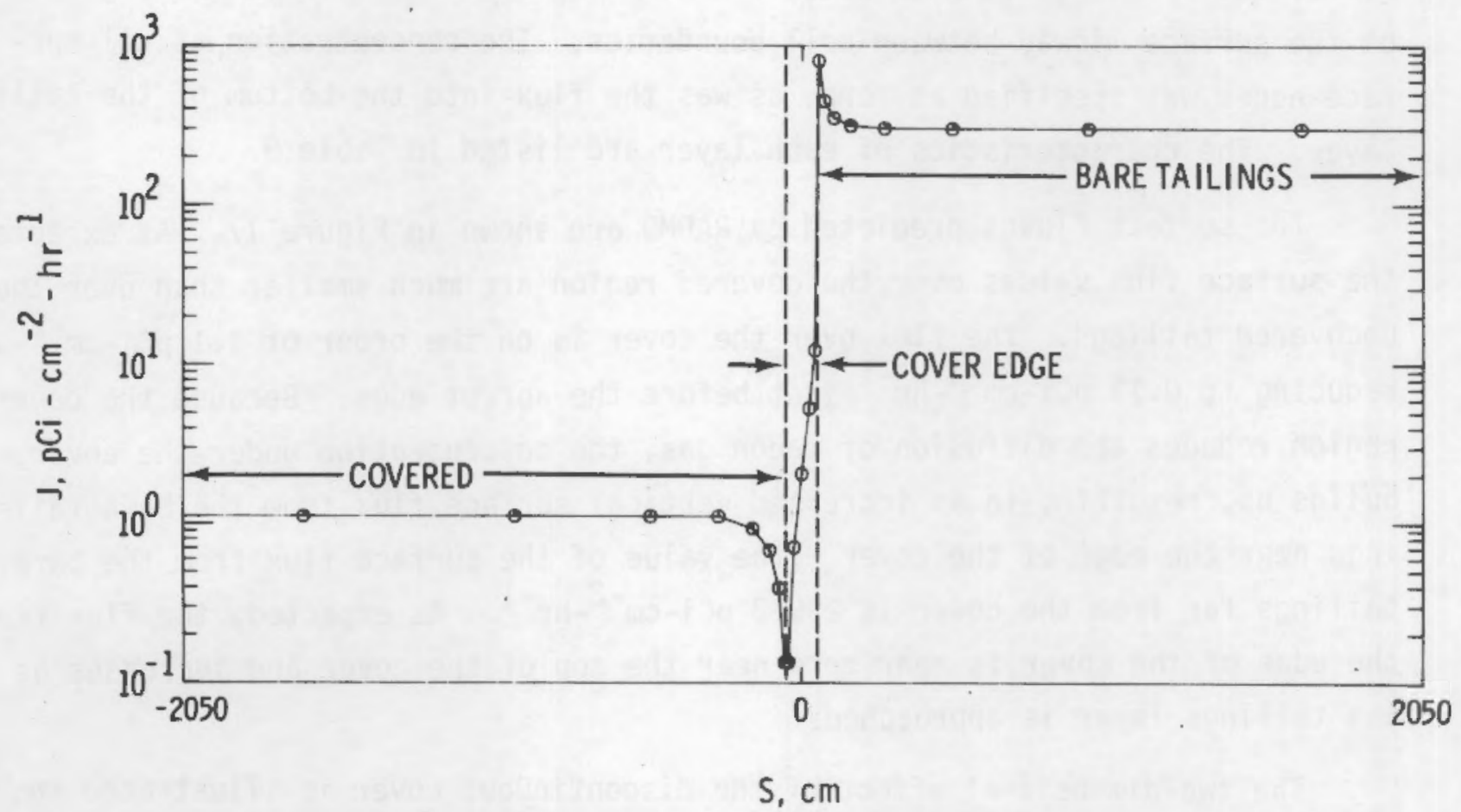

FIGURE 17. Surface Flux Versus Surface Distance ( $S=0$ at midpoint of cover edge) 


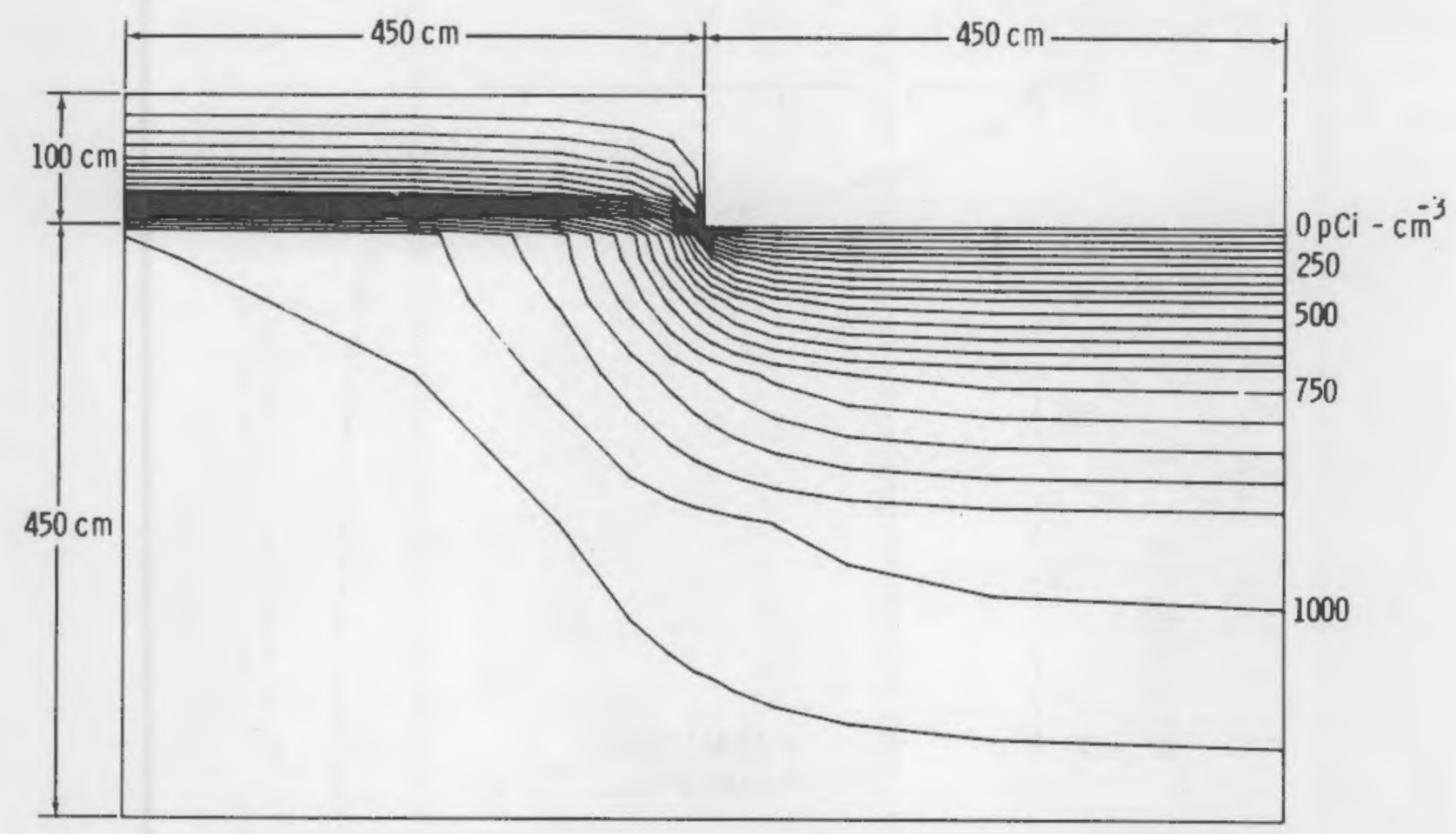

FIGURE 18. Concentration Profiles for Discontinuous Cover (50 $\mathrm{pCi}-\mathrm{cm}^{-3}$ interval)

Figure 16. Figure 20 is the concentration profile for the far right column of cel1s. The analytic solution shown in Figure 19 was computed using RADON1, while the analytic solution shown in Figure 20 is obtained from Equation (12). The match with the analytic solution for concentration is excellent. The surface flux from the cover predicted by RADMD is within $1.6 \%$ of the analytic solution computed using Equation (11). The bare tailings' surface flux computed by RADND is within $3 \%$ of the analytic solution computed using Equation (13). This accuracy demonstrates that the multidimensional radioactive diffusion code can simulate steady-state, two-dimensional radon diffusion. Further applications are required to verify the accuracy of the transient solution, and the code should be verified against a two-dimensional analytic solution. In summary, the preliminary modeling results are extremely encouraging. Further development will allow us to account for varying moisture contents in twodimensional tests. In addition, convective transport of radon gas can be readily simulated using RADMD when the need arises. 


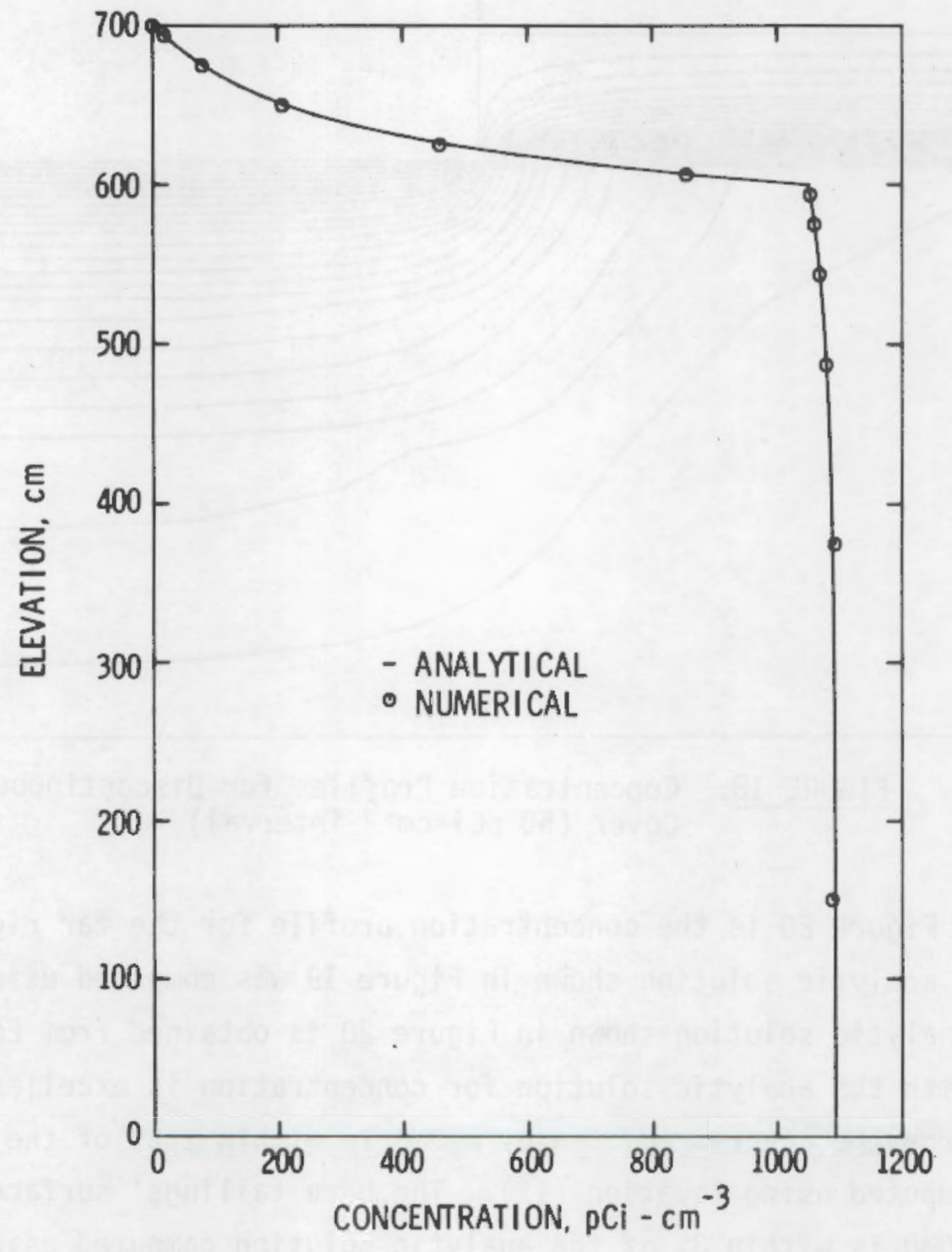

FIGURE 19. Analytical Versus Numerical Solution Tailings $(600 \mathrm{~cm})$ with Cover $(100 \mathrm{~cm})$ 


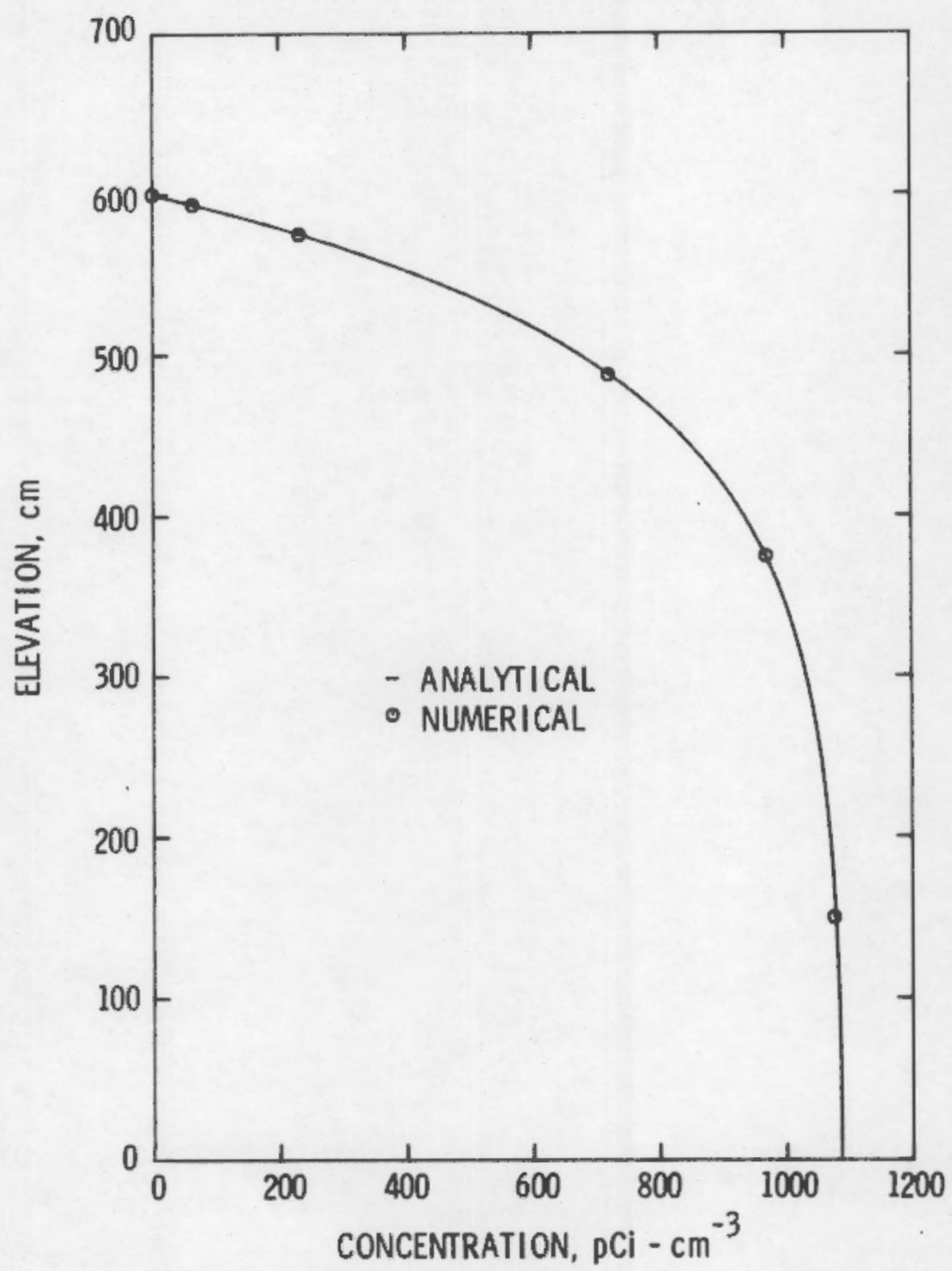

FIGURE 20. Analytical Versus Numerical Solution Bare Tailings $(600 \mathrm{~cm})$ 



\section{REFERENCES}

Ames, W. F. 1977. Numerical Methods for Partial Differential Equations. 2nd Edition, Academic Press, New York.

Edwards, A. L. 1972. TRUMP: A Computer Program for Transient and Steady-State Temperature Distributions in Multidimensional Systems. Report No. UCRL14754, Rev. 3, Lawrence Livermore Laboratory, University of California, Livermore, California.

Gupta, S. K., K. K. Tanji, D. R. Nielsen, J. W. Biggar, C. S. Simmons and J. L. MacIntyre. 1978. Field Simulation of Soil-Water Movement with Crop Water Extraction. Water Science and Engineering Papers №. 4013, Department of Land, Air, and Water Resources, University of California, Davis, California.

Key, K. T., T. N. Narasimhan, A. E. Reisenauer and R. W. Nelson. 1981. TRUST: A COMPUTER PROGRAM FOR SATURATED-UNSATURATED FLOW IN DEFORMABLE POROUS MEDIA. PNL-3975, Pacific Northwest Laboratory, Richland, Washington.

Narasimhan, T. N. and P. A. Witherspoon. 1977. "Numerical Model for SaturatedUnsaturated Flow of Deformable Porous Media 1. Theory." In: Water Resources Research, 13(3):657-664.

Nelson, R. W., G. W. Gee and C. A. Oster. 1980. "Radon Control by Multilayer Earth Barriers, 1. Modeling of Moisture and Density Effects on Radon Diffusion from Uranium Mill Tailings." In: Uranium Mill Tailings Management, Proceedings of the Third Symposium, November 24-25, 1980, pp. 79-88. Geotechnical Engineering Program, Civil Engineering Department, Colorado State University.

Rogers, V. C., G. M. Sandquist and K. K. Nielson. 1981. Radon Attenuation Effectiveness and Cost Optimization of Composite Covers for Uranium Mi11 Tailings. RAE 9-1, Rogers and Associates, Salt Lake City.

Simmons, C. S. and G. W. Gee. 1981. Simulation of Water Flow and Retention in Cover Materials Overlaying Uranium Mill Tailings. PNL-3877, Pacific Northwest Laboratory, Richland, Washington.

Tanner, A. B. 1964. "Radon Migration in the Ground: A Review." In The Natural Radiation Environment, ed. J. A. S. Adams and W. M. Lowder, pp. 161-190. University of Chicago Press.

von Rosenberg, D. U. 1969. Methods for the Numerical Solution of Partial Differential Equations. pp. 114-115. American Elsevier Publishing Company, Inc. 

UMT /0204

PNL-3989

DISTRIBUTION

UC-70

No. of

Copies

OFFSITE

A. A. Churm

DOE Patent Division

9800 S. Cass Avenue

Argonne, IL 60439

27 DOE Technical Information Center

William E. Mott, Director

Environmental and Safety

Engineering Division

U.S. Department of Energy, EP-14 Washington, DC 20545

Robert W. Ramsey, Jr., Program Mgn Remedial Actions Program, NE-301

U.S. Department of Energy

Washington, DC 20545

E. Delaney, Remedial Actions Program

office of Nuclear Waste Management

U.S. Department of Energy, NE-30I

Washington, DC 20545

20 Donald H. Groelsema

Remedial Actions Program

Office of Nuclear Waste Management

U.S. Department of Energy, NE-301

Washington, DC 20545

A. Kluk, Remedial Actions Program Office of Nuclear Waste Management U.S. Department of Energy, NE-301 Washington, DC 20545

Ross A. Scarano, Chief

Uranium Recovery License Branch

Mail Station 483-5S

U.S. Nuclear Regulatory Commission

Washington, DC 20555
No. of

Copies

William Nixon

Office of Nuclear Materials, Safety and Safeguards

Mail Station 396-SS

U.S. Nuclear Regulatory Commission Washington, DC 20555

George Birchard

Mail Station 1130-SS

U.S. Nuclear Regulatory Commission

Washington, DC 20555

Stanley Lichtman, Criteria and

Standards Division

Office of Radiation Programs

U.S. Environmental Protection Agency

Washington, DC 20460

J. White, Chief

Reactor Operations Branch

U.S. Department of Energy

Richland, Operations Office

825 Jadwin Avenue

P.0. Box 550

Richland, WA 99352

J. G. Themelis, Director

Engineering and Safety Division

DOE Grand Junction Office

2597 B-3/4 Road (South Redlands)

P. 0 . Box 2567

Grand Junction, CO 81501

E. L. Keller, Director

Technical Services Division

U.S. Department of Energy

Oak Ridge Operations Office

P.0. Box E

Oak Ridge, TN 37830

Thomas M. Gerusky, Director

Bureau of Radiation Protection

P.0. Box 2063

Harrisburg, PA 17120 
No. of

Copies

Albert J. Hazle, Director

Radiation and Hazardous Wastes

Division

Colorado Department of Health

4210 East 11 th Avenue

Denver, CO 80220

Edgar D. Bailey, Administrator

Radiation Control Branch

Texas Department of Health

1100 W. 49th Street

Austin, TX 78756

Larry Anderson, Director

Bureau of Radiation and

Occupational Health

P.0. Box 2500

Salt Lake City, UT 84110

Wa it Ackerman, Director

Departiment of Environmental Quality

Land Quality Division

Hathaway Building

Cheyenne, WY 82002

Lynn Fitzrandolph

Arizona Atomic Energy Commission

2929 West Indian School Road

Phoenix, AZ 85017

Ted Wolfe, Environmental. Manager

Radiation Department

P.0. Box 968

Santa Fe, NM 87503

Lynn Frank, Director

Oregon Department of Energy

111 Labor and Industries Building

Salem, Oregon 97310

Dana K. Mount, Director

Division of Environmental Engineering

North Dakota State Department of

Health

1200 Missouri Avenue, Room 304

Bismarck, ND 58505
No. of

Copies

Robert Funderberg

Department of Health and Welfare

Statehouse

Boise, Idaho 83707

Harold Tso, Executive Director

Environmental Protection Commission

The Navajo Nation

Window Rock, AZ 86515

2 John W. McKiernan

Organization 4542

Sandia National Laboratory-Albuquerque P.0. Box 5800

Albuquerque, NM 87185

Paul O'Brien

Organization 4541

Sandia National Laboratory-A1buquerque P.0. Box 5800

Albuquerque, NM 87185

Dr. Gergely Markos

Research Institute for Geochemistry and Environmental Chemistry

2693 Commerce Road

Rapid City, SD 57701

Walt Kisieleski

Argonne National Laboratory

9700 South Cass Avenue

Argonne, IL 60439

John D. Nelson, Ph.D., P.E.

Professor, Program Leader

Colorado State University

Fort Collins, CO 80523

D. E. Large, Program Manager

Radioactive Waste Management Program

Oak Ridge Operations office

P.0. Box E

Oak Ridge, TN 37830 
No. of

Copies

A. A. Metory

Weston

Weston Way

West Chester, PA 19380

R. Neff

Mound Facility

c/o Dayton Area Office

P.0. Box 66

Miamisburg, $\mathrm{OH} 45342$

K. R. Porter

Dames \& Moore

1626 Cole Blvd

Golden, CO 80401

A. Ryon

Oak Ridge National Laboratory

P.0. Box $X$

Oak Ridge, TN 37830

T. N. Narasimhan

Lawrence Berkeley Laboratory

Berkeley, CA 9472D

T. Tamura

Oak Ridge National Laboratory

P.0. Box X

Oak Ridge, TN 37830

George Stukenbroeker

NLO, Inc.

P.0. Box 39158

Cincinnati, $\mathrm{OH} 45239$

Alvin Askew

Politech Corporation

2220 Austin National Bank Tower

Austin, TX 78701

M. L. Matthews, Project Engineer

Uranium Mill Tailings Project Office

U.S. Department of Energy

P.0. Box 5400

Albuquerque, NM 87115
No. of

$\underline{\text { Copies }}$

50 R. H. Campbell, Project Manager

Uranium Mill Tailings Project Office

U.S. Department of Energy

P.0. Box 5400

Albuquerque, NM 87115

Vern C. Rogers, President

Rogers \& Associates Engineering

445 East 200 South, Suite 303

Salt Lake City, UT 84111

Robert Overmyer

Ford, Bacon \& Davis Utah

375 Chipeta Way

P.0. Box 8009

Salt Lake City, UT 84108

Dave Dreesen

Los Alamos National Laboratory

P.0. Box 1663

Los Alamos, NM 87545

\section{ONSITE}

DOE Richland Operations Office

H. E. Ransom

78 Pacific Northwest Laboratory

S. M. Brown

J. L. Buelt

L. L. Cadwe11

D. B. Cearlock

J. Cline

G. W. Gee (15)

J. N. Hartley

T. L. Jones

J. M. Latkovich

D. W. Mayer (15)

R. W. Nelson (15)

C. A. Oster (15)

W. B. Silker

L. C. Schwendiman

D. A. Zimmerman

Publishing Coordination (2)

Technical Information (5) 
